University of Louisville

ThinkIR: The University of Louisville's Institutional Repository

Electronic Theses and Dissertations

4-2008

\title{
A MEMS Knudsen pump for high gas flow applications.
}

Davor Copic

University of Louisville

Follow this and additional works at: https://ir.library.louisville.edu/etd

\section{Recommended Citation}

Copic, Davor, "A MEMS Knudsen pump for high gas flow applications." (2008). Electronic Theses and Dissertations. Paper 277.

https://doi.org/10.18297/etd/277

This Master's Thesis is brought to you for free and open access by ThinkIR: The University of Louisville's Institutional Repository. It has been accepted for inclusion in Electronic Theses and Dissertations by an authorized administrator of ThinkIR: The University of Louisville's Institutional Repository. This title appears here courtesy of the author, who has retained all other copyrights. For more information, please contact thinkir@louisville.edu. 


\title{
A MEMS KNUDSEN PUMP FOR HIGH GAS FLOW APPLICATIONS
}

\author{
By \\ Davor Copic \\ B.S., University of Louisville, 2008

\begin{abstract}
A Thesis
Submitted to the Faculty of the

Graduate School of the University of Louisville in Partial Fulfillment of the Requirements

for the Degree of
\end{abstract}

\author{
Master of Engineering \\ Department of Mechanical Engineering \\ University of Louisville \\ Louisville, Kentucky
}

April 2008 

Copyright 2008 by Davor Copic

All rights reserved 


\section{A MEMS KNUDSEN PUMP FOR HIGH GAS FLOW APPLICATIONS}

\section{By}

Davor Copic

B.S., University of Louisville, 2008

A Thesis Approved on

April 7, 2008

by the following Thesis Committee:

Dr. Shamus McNamara, Thesis Director

Dr. Ellen Brehob, Committee Member

Dr Bruce Alphenaar, Committee Member 


\section{DEDICATION}

This thesis is dedicated

to my girlfriend Jennifer Anne Ellison,

to my sister Sara Copic,

and to my parents Aida Copic and Gene Thomas Copic

without whom I would not have gotten this far. 


\section{ACKNOWLEDGEMENTS}

I would like to sincerely express my gratitude to my thesis advisor, Dr. Shamus McNamara, for his enthusiasm and inspiration, patience and guidance. My thanks goes out to my colleagues Kunal Pharas, Chakravarthy Yamarthy, and Scott Cambron. For their encouragement and mentorship I would like to thank Ron Manginell, Greg Shelmidine, Jim Spates, and Doug Adkins. Last but not least, I would like to thank my family in Sarajevo, Köln, Edinburgh, and Chicago. 


\section{ABSTRACT \\ A MEMS KNUDSEN PUMP FOR HIGH GAS FLOW APPLICATIONS \\ Davor Copic}

April 7, 2008

The Knudsen pump works on the principle of thermal transpiration. As a result of requiring a thermal gradient, channel hydraulic diameter smaller than the mean free path of the gas being pumped, and having no moving parts, the Knudsen pump features a simple and attractive design. The focus of this thesis is to develop a general relation for the ideal pump efficiency as well as to quantify thermal losses in the efficiency equation to predict the efficiency of fabricated pumps. Understanding the efficiency will enable a better understanding of the practical limits of the pump's ability to transfer energy from a heat gradient to kinetic energy, in terms of flow rate, potential energy, and pressure gradient, generating a greater understanding of the applications for which the pump is best suited. Test method and results for a MEMS fabricated pump are provided. Thermal simulations of two designs are presented. 


\section{TABLE OF CONTENTS}

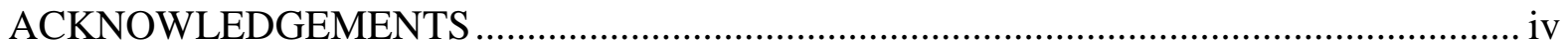

ABSTRACT

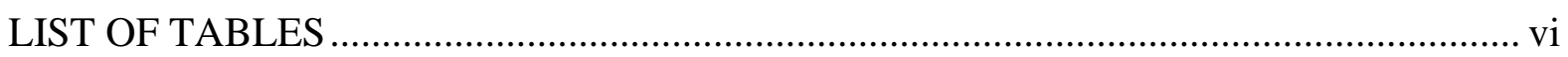

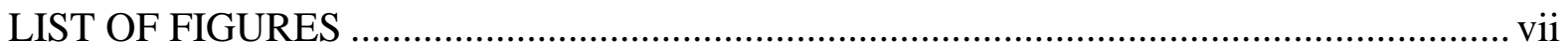

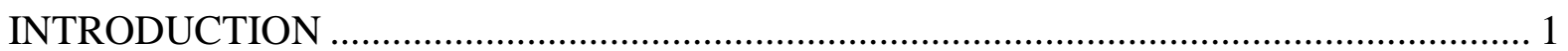

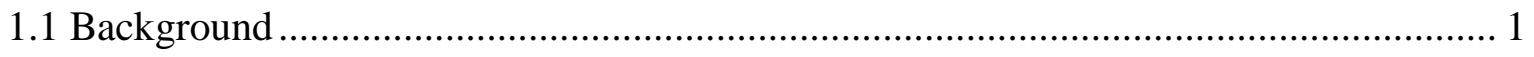

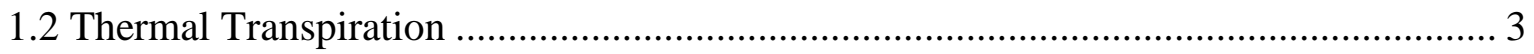

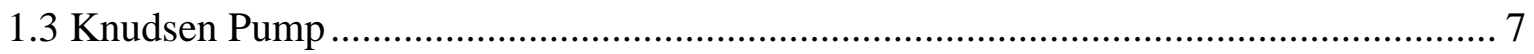

1.4 Review of Other Thermal Pumps..............................................11

1.5 Outline

KNUDSEN PUMP EFFICIENCY WITH NO THERMAL LOSSES ................................... 13

2.1 Knudsen Pump Ideal Efficiency though an Aperture ………………............................ 13

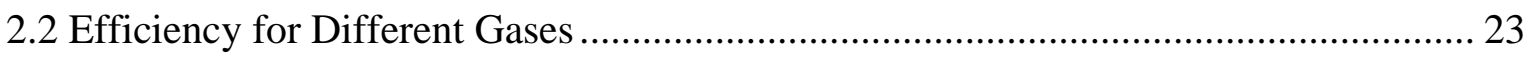

KNUDSEN PUMP EFFICIENCY INCLUDING THERMAL LOSSES .............................. 25

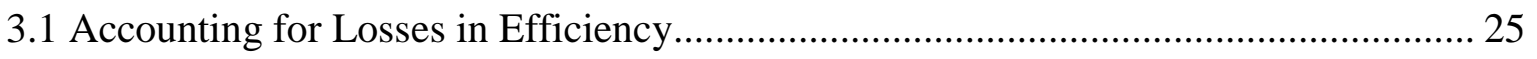

3.2 Accounting for Geometry Specific Losses in Efficiency ............................................. 29

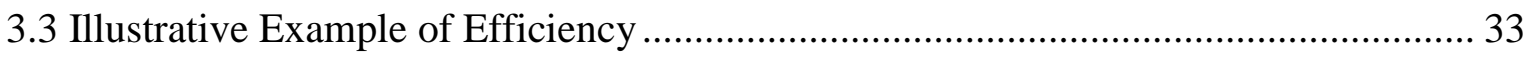

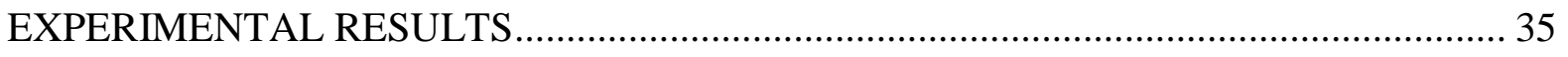

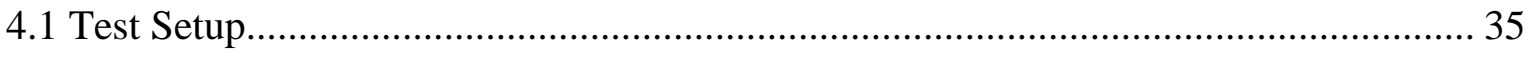

4.2 Method to Calculate Pump Efficiency ………………………................................ 38 
4.3 Method to Calculate Channel Height................................................................. 39

4.4 Method to Calculate Pump Flow Rate ................................................................. 40

4.5 Overview of Fabrication Procedure ................................................................. 41

Experimental Pump Measurements .................................................................... 43

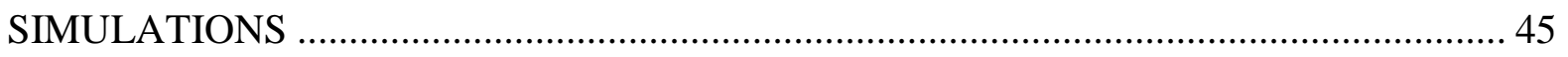

5.1 Simulation Overview ................................................................................ 45

5.2 Simulation of Current Design .................................................................... 45

5.3 Simulation of Design with suspended Heater ..................................................... 48

CONCLUSIONS AND FUTURE RESEARCH DIRECTIONS .................................... 52

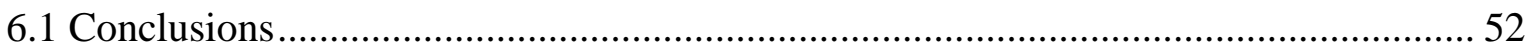

6.2 Potential Application to be investigated ......................................................... 53

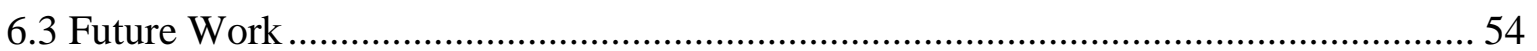




\section{LIST OF TABLES}

Table 1. Flow regimes and associated Knudsen number ranges $[12] \ldots \ldots \ldots \ldots \ldots \ldots \ldots \ldots$

Table 2. Conditions that impact the efficiency of the pump.......................... 13

Table 3. Maximum efficiencies of selected gases.................................23

Table 4. Analogous fluid system compared to electrical system.......................25

Table 5. Characteristics of tested pump.......................................41 


\section{LIST OF FIGURES}

Figure 1. Two chambers separated by an aperture each having its own pressure and

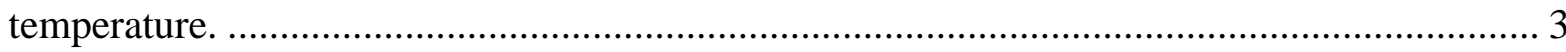

Figure 2. Large channel in transition flow, figure taken from [13] ................................... 5

Figure 3.Knudsen pump with rectangular channels, figure taken from [17] ....................... 8

Figure 4. Knudsen pump fabricated using Zeolite, a nano-porous material, figure from [18]. 9

Figure 5. Knudsen Pump design, which may be cascaded to create a greater pressure ratio. 10

Figure 6. Detailed view of the flux through an aperture................................................. 14

Figure 7. Enlarged view of aperture for power consideration. ....................................... 16

Figure 8. Surface of ideal efficiency as a function of $T_{\text {cold }}$ and $T_{h o t}$, using the constraint

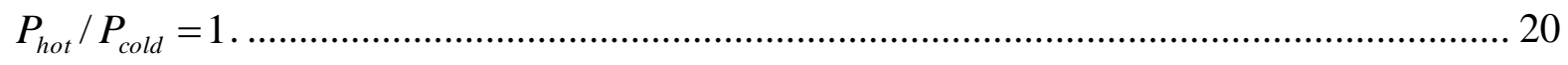

Figure 9. Plot of efficiency vs. temperature ratio for air. ............................................ 21

Figure 10. Pressure on the hot side in Pascals versus efficiency for a temperature ratio of 1.5.

Figure 11.Pressure on the cold side in Pascals versus efficiency for a temperature ratio of 1.5.

Figure 12. Efficiencies of selected gases plotted versus the temperature ratio.

Figure 13. Knudsen pump with a rectangular channel heated to temperature and the losses associated with this.

Figure 14. Efficiency from the illustrative example as a function of the temperature on the hot side. 


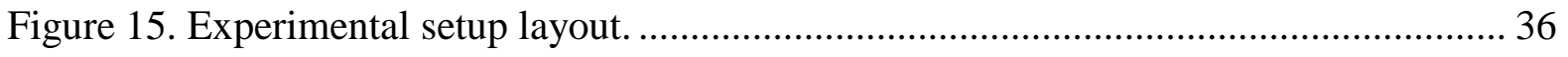

Figure 16. Detailed view of fixture and how the seals are formed........................................ 37

Figure 17. Detail of plastic cover which provides pressure to form the seal between the chip

and the fixture.

Figure 18. Fabrication Procedure, figure created by Kunal Pharas [24]............................... 41

Figure 19. Top view of pump prior to bonding the glass chip to form the channel. .............. 42

Figure 20. Pressure on the hot side of the pump (ambient) and the cold side....................... 43

Figure 21. Cross-section of the chip shows the channel from pump design in section 4.4... 45

Figure 22. Detail of the heater trace and cross-section of the channel from the pump design in

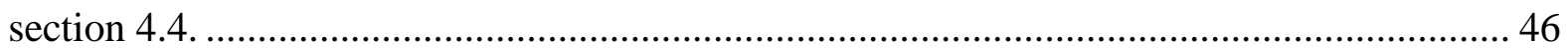

Figure 23. Temperature distribution along channel generated by a gold heater trace on the

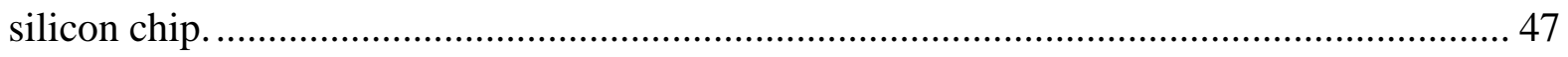

Figure 24. Detailed view of temperature distribution along channel..................................... 47

Figure 25. Temperature distribution along the channel for the design detailed in section 4.448

Figure 26. Improved design layout and material selection................................................. 49

Figure 27. Detail of improved heater design, which is suspended from the bond pad........... 49

Figure 28. Temperature distribution in the fixture using suspended heater design. ............... 50

Figure 29. Temperature distribution in the suspended heater............................................. 50 


\section{CHAPTER I}

\section{INTRODUCTION}

\subsection{Background}

Microelectromechanical systems (MEMS) is a term that was coined during the late nineteen eighties in the United States in order to classify a multidisciplinary field, which emerged from the integrated circuit (IC) industry and associated technologies. In Europe, this field is known as Microsystems Technology (MST) and in Japan, as Micromachines [1]. MEMS deal with the creation of various micro scale devices, structures, and the study of effects that are dominant on this scale. As a result of the complex phenomenona that take place on the micro scale, designing and fabricating a device is an interdisciplinary effort. Often physicists, chemists, biologists, electrical and mechanical engineers collaborate on MEMS devices.

MEMS processes simply extend the ability to construct objects. Much like steel working allowed the construction of large structures such as bridges and oil rigs, MEMS processes allow for the creation of minuscule structures and devices. Many MEMS devices that the general public relies on have been created by miniaturization. Examples include pressure sensors [2], accelerometers [3], chemical sensors [4], mechanical gears [5], and actuators [6]. Other devices have been conceived specifically for the fabrication with MEMS processes. One example of this is the deformable mirror array (DMA) found in high definition optical displays [7]. 
In the development of MEMS, the ability to manipulate silicon and other deposited materials on a micrometer scale has been crucial and is generally referred to as micromachining. Lithography is one of the processes essential to machining silicon, and it stems directly from the IC industry. Many other processes, such as thin film deposition, and processes changing the electrical properties of silicon also stem from the IC industry. Lithography is the successive addition and patterning of films on the silicon surface and then transferring the pattern to the silicon itself. The same procedure is also used to pattern films grown or deposited on the silicon. Many excellent textbooks can be found on the fabrication of MEMS devices [6, 8], where these processes are discussed in detail. It is not uncommon to incorporate embedded circuits with actuators and structures to obtain integrated systems [3], since many of the processes involved in MEMS fabrication are derived from the IC industry.

Some of the advantages MEMS fabricated devices offer over macro scale devices stem from integration, while batch processing allows MEMS devices to be fabricated in large numbers at greatly reduced costs per device. Other advantages come from miniaturization, such as a further reduction in cost and expanding the application of the device. For instance, the ability to add miniaturized pressure sensor to catheters improves their functionality. Miniaturization also offers MEMS devices the ability to operate under principles which only become significant at the micrometer or even nanometer scale.

One such principle is thermal transpiration, which is a thermally driven effusion of molecules. One device which makes use of this phenomenon is the Knudsen pump, which has no moving parts and has the potential to change the way gases are manipulated on a micro and macro scale. The effect in relation to a pump was first studied and documented by Martin Knudsen[9]. The pump only works if fabricated features are similar in size to the 
mean free path of the gas being pumped, approximately $60 \mathrm{~nm}$ for air at atmospheric pressure. With the advent of MEMS, instead of increasing the mean free path of the gas, the pump can be shrunk, greatly increasing the potential applications for such a pump.

\subsection{Thermal Transpiration}

In a series of lectures, formalized in his Kinetic Theory of Gases: Some Modern Aspects in 1910 [9], Martin Knudsen documents the use of thermal transpiration, a rarefied gas transport phenomenon, and its application toward a pump, whose design now bears his name. During this time the effect was known as thermal molecular pressure and later became known as thermal creep flow $[10,11]$. Knudsen attempted to explain the phenomenon both through theory and through experiments. Some of the equations he derived are still in use today. To illustrate his derivation consider two adjacent chambers separated by an aperture with a diameter smaller then the mean free path of the gas (Figure 1).

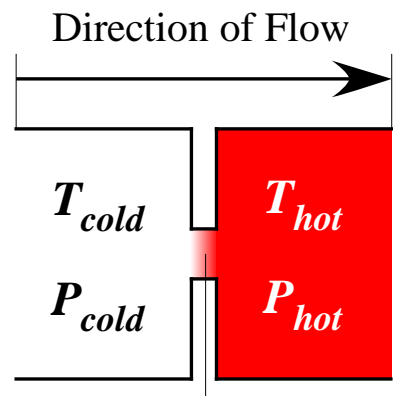

Small Aperture

Figure 1. Two chambers separated by an aperture each having its own pressure and temperature.

One of the chambers is heated and has a temperature and pressure corresponding to $T_{h o t}$ and $P_{h o t}$, respectively, while the other chamber has a lower temperature and pressure corresponding to $T_{\text {cold }}$ and $P_{\text {cold }}$, respectively. As the temperature ratio $\left(T_{\text {hot }} / T_{\text {cold }}\right)$ increases more molecules will diffuse from the cold to the hot side, despite the opposing pressure 
gradient. A net gas flow rate will continue until the diffusing molecules increase the pressure in the hot chamber sufficiently that the pressure driven flow equals the diffusion driven flow. The pressure ratio at which this occur is described by Knudsen [9] by

$$
\frac{P_{\text {hot }}}{P_{\text {cold }}}=\sqrt{\frac{T_{\text {hot }}}{T_{\text {cold }}}} .
$$

The equilibrium condition described by equation (1) is noted by Knudsen to be different from the expected $P_{\text {cold }}=P_{\text {hot }}$ result. This is due to diffusion being the main mode of mass transport instead of bulk fluid motion. The result from equation (1) was obtained by equating the flux of molecules passing through the aperture from the cold and hot sides. The flux is described using

$$
\Gamma=\frac{P}{\sqrt{2 \pi \cdot \bar{R} \cdot T}}
$$

where $\Gamma$ is the mass flux, $P$ is the pressure, $T$ is the temperature, and $\bar{R}$ is the specific gas constant.

As stated previously in the discussion of the two adjacent chambers, the thermal transpiration effect will only occur if the aperture is sufficiently small compared to the mean free path of the gas. The ratio of the mean free path to the characteristic dimension was defined by Knudsen using

$$
K n=\frac{\lambda}{h}
$$

where $K n$ is the Knudsen number, $\lambda$ is the mean free path, and $h$ is the characteristic dimension. For a rectangular channel $h$ is the height of the smallest dimension, while for a circular channel $h$ is the diameter. The mean free path of a gas is calculated using 


$$
\lambda=\frac{1}{\sqrt{2} \pi d_{m}^{2}(\rho / m)}
$$

where $\rho$ is the density, $m$ is the molecular mass, and $d_{m}^{2}$ is the radius of the influence range of the intermolecular force [11]. Considering equation (4) in conjunction with the ideal gas law it becomes apparent that the mean free path can be decreased by increasing the density or the pressure, or by decreasing the temperature. The thermal transpiration dominates the flow if the gas can be considered in molecular flow. For this, the Knudsen number needs to be greater than one. Thermal transpiration is present throughout the entire range of Knudsen numbers, but the pressure flow dominates the low Knudsen number range. The flow regimes and the associated Knudsen number ranges are shown in Table 1.

\begin{tabular}{|c|c|}
\hline Regime & Knudsen number range \\
\hline Molecular & $K n>0.5$ \\
\hline Transitional & $0.5>K n>0.01$ \\
\hline Continuum & $K n<0.01$ \\
\hline
\end{tabular}

Table 1. Flow regimes and associated Knudsen number ranges [12].

Figure 2 shows a channel in transition flow whose characteristic dimension is substantially greater than the mean free path [13].

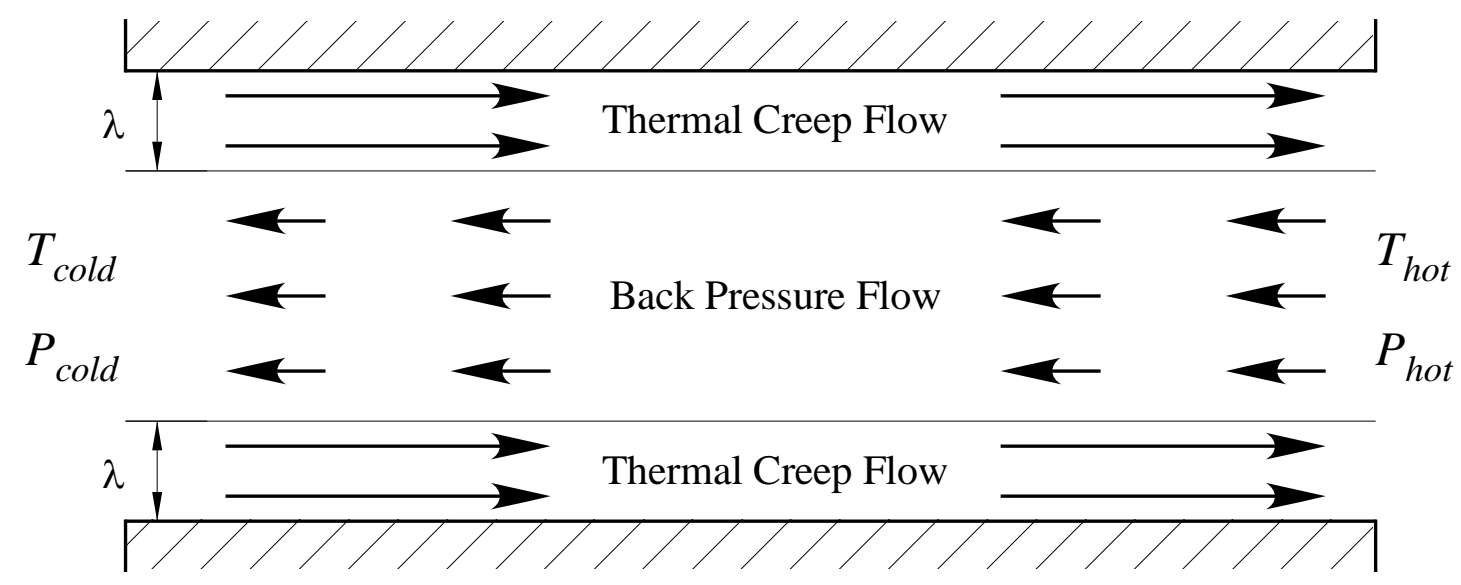

Figure 2. Large channel in transition flow, figure taken from [13]. 
The slow return flow is due to the pressure difference, while the thermal creep flow is due to a temperature gradient along the channel wall. Munz et. al. have shown that the power consumption of a series of cascaded pumps is greatly reduced by allowing operation during the transition stage, where both the pressure and the thermal transpiration flow are significant [14]. The efficiency of the pump is reduced as the differential pressure increases due to thermal transpiration moving molecules against the pressure gradient.

A key aspect of thermal transpiration in regards to the Knudsen pump is the flow that can be generated. The generated mass flow rate through an aperture is obtained by multiplying the flux by the cross-sectional area of the aperture. Muntz and his group have done substantial work on the Knudsen pump and the thermal transpiration effect through long channels in transitional flow [14]. They obtain the following equation for the mass flow through a capillary tube:

$$
\dot{M}=P_{\text {avg }} \sqrt{\frac{m}{2 k T_{\text {avg }}}} A\left(\frac{L_{r}}{L_{x}} \frac{\Delta T}{T_{\text {avg }}} Q_{T}-\frac{L_{r}}{L_{x}} \frac{\Delta P}{P_{\text {avg }}} Q_{P}\right)
$$

where $\Delta P$ is the pressure difference, $P_{\text {avg }}$ is the average pressure in the capillary tube, $\Delta T$ is the temperature difference, $T_{\text {avg }}$ is the average temperature in the capillary tube, $Q_{T}$ is the transpiration flow coefficient, $Q_{P}$ is the pressure return flow coefficient, $A$ is the capillary's cross-sectional area, $L_{r}$ is the radius of the capillary tube, $L_{x}$ is the length of the capillary tube, $m$ is the molecular mass of the gas, and $k$ is Boltzmann's constant [15]. The pressure return flow and transpiration flow coefficient are dependent on the Knudsen number and describe the transition flow. With increasing Knudsen numbers the $Q_{T} / Q_{P}$ ratio increases [13].

Monte Carlo simulations are useful in simulating the gas flows associated with thermal transpiration. The gas flows are difficult to model with continuum-based simulations 
due to the fact that a minimal number of gas-gas collisions are accounted for using this method. Monte Carlo simulations are efficient for the free molecular flow regime, preferred for operation of a single stage Knudsen pump. A recent study comparing scattering kernels, the analytical probability distributions of the behavior of molecules after collision with a surface, suggest that a Maxwell kernel does not give good results for moderately long channels [16]. The Maxwell kernel assumes that a fraction of the molecules that collide with a surface diffuse radially, while the other molecules are reflected specularly and is used to determine the power to which the temperature ratio is taken in equation (1).

\subsection{Knudsen Pump}

The Knudsen pump, conceived by Martin Knudsen in 1910 [9], is a pump that utilizes the rarefied gas transport phenomenon called thermal transpiration. For the pump to work, however, the characteristic dimension of the pump (i.e. height of channel or the diameter) has to be similar in length to the mean free path of the gas being pumped. Until 1990, the prototypes of the pump had to accomplish this by either increasing the mean free path to the size of the characteristic dimension or by creating pinholes in a membrane [9]. MEMS fabrication has allowed the miniaturization of the Knudsen pump [17]. The Knudsen pump has the advantage over macro scale pumps, that it does not suffer from reduced life cycles due to various modes of mechanical failure. The Knudsen pump has the potential to replace some macro scale pumps. Applications to which this is most critical include gas preconcentration for chemical sensors, gas chromatography applications, spectroscopy, moving gases on chip, forced convection cooling, power scavenging, and micro actuators. The broader impacts of a well developed Knudsen pump include a mass migration of many 
sensors and actuators from the bench top to an on-chip-configuration, furthering research in the field of MEMS.

Two different approaches have been developed for fabricating a Knudsen pump sufficiently small to operate under atmospheric pressures. A potential solution involves the stacking of a porous material such as Zeolite to obtain a partially microfabricated pump [18]. The key problem associated with this method of fabrication is that integration with MEMS devices such as chemical sensors may not be possible, limiting the applications of the pump. A reduction in efficiency due to winding channels is also a potential problem of these types of pumps. An alternative fabrication method involves using MEMS technologies to fabricate a rectangular channel [17] that can be integrated on chip with other MEMS devices, extending their usefulness and range of operation. A device of this type fabricated by McNamara et. al. is shown in Figure 3 for clarity.

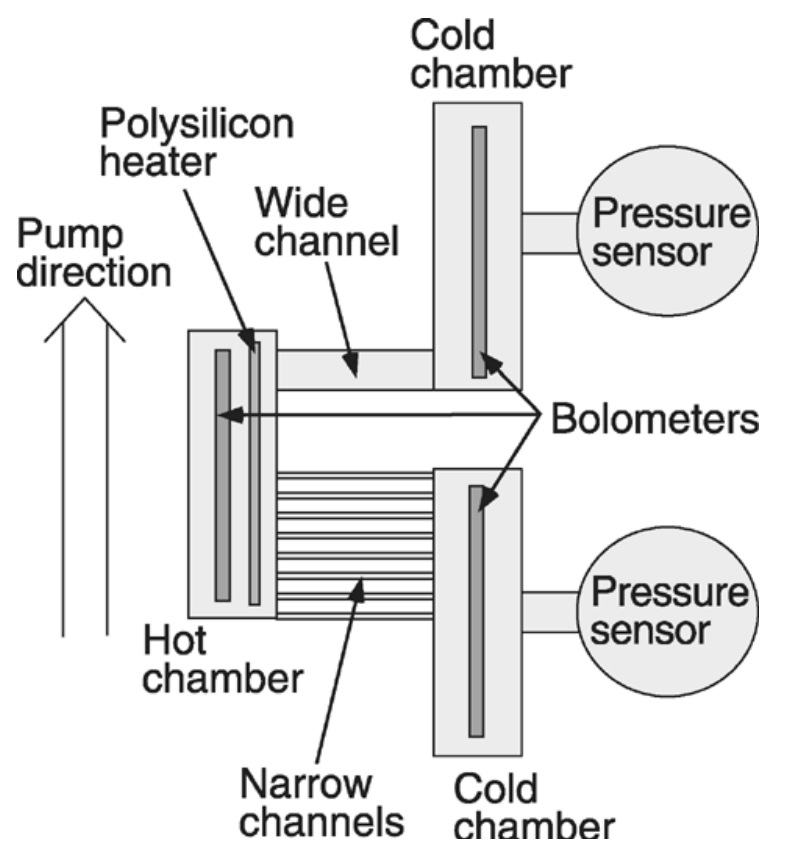

Figure 3. Knudsen pump with rectangular channels, figure taken from [17]. 
The Knudsen pump shown above uses a temperature gradient along the narrow channels to pull air from the bottom cold side to the hot side via thermal transpiration, while the expansion of gases in the hot chamber pushes air through the wide channel via bulk movement to the top cold chamber. This pump was integrated with MEMS pressure sensors on the chip. The flow rate of this type of pump can be increased by using rectangular channels with high aspect ratios, as this would maintain the height of the channel while increasing the overall cross-sectional area.

Recently Knudsen pumps that use pores in Zeolite as channels [18], have demonstrated that a max pressure difference of $2.5 \mathrm{kPa}$ can be obtained and that under different conditions the max volumetric flow rate of $0.12 \mathrm{SCCM}$ is attainable, both were achieved with a temperature difference of $38 \mathrm{~K}$. Similar values for flow rate per area can be obtained by the fully MEMS fabricated pump. A schematic detailing this design for clarification purposes is shown in Figure 4.

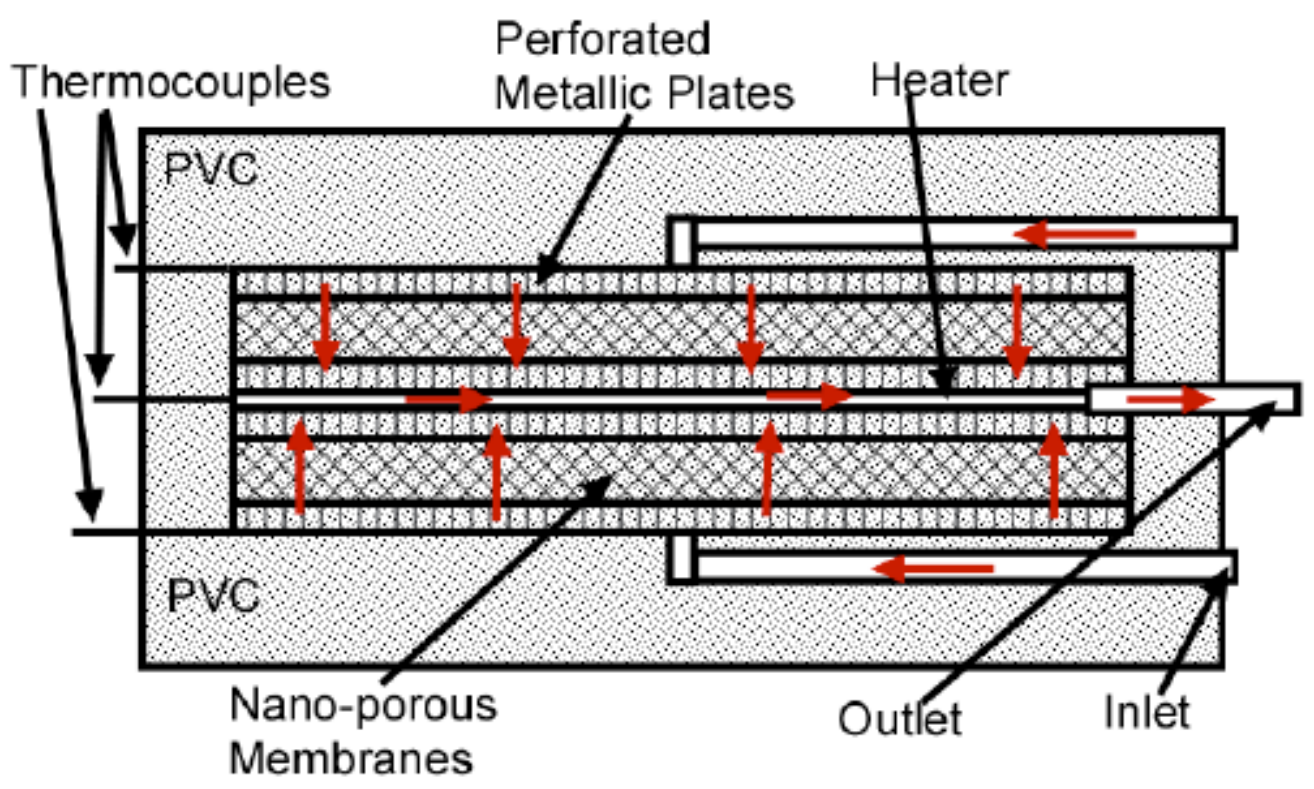

Figure 4. Knudsen pump fabricated using Zeolite, a nano-porous material, figure from [18]. 
The Knudsen pump shown above heats the two Zeolite disks via a central heater and pulls the air through them to the outlet in the center of the stack. The airflow is indicated with the red arrows.

Both of these designs can be cascaded (connected in series) and arrayed (connected in parallel). A multistage pump can obtain a higher pressure ratio than described in equation (1) while using the same change in temperature. The single stage of such a pump is illustrated in Figure 5 [13].

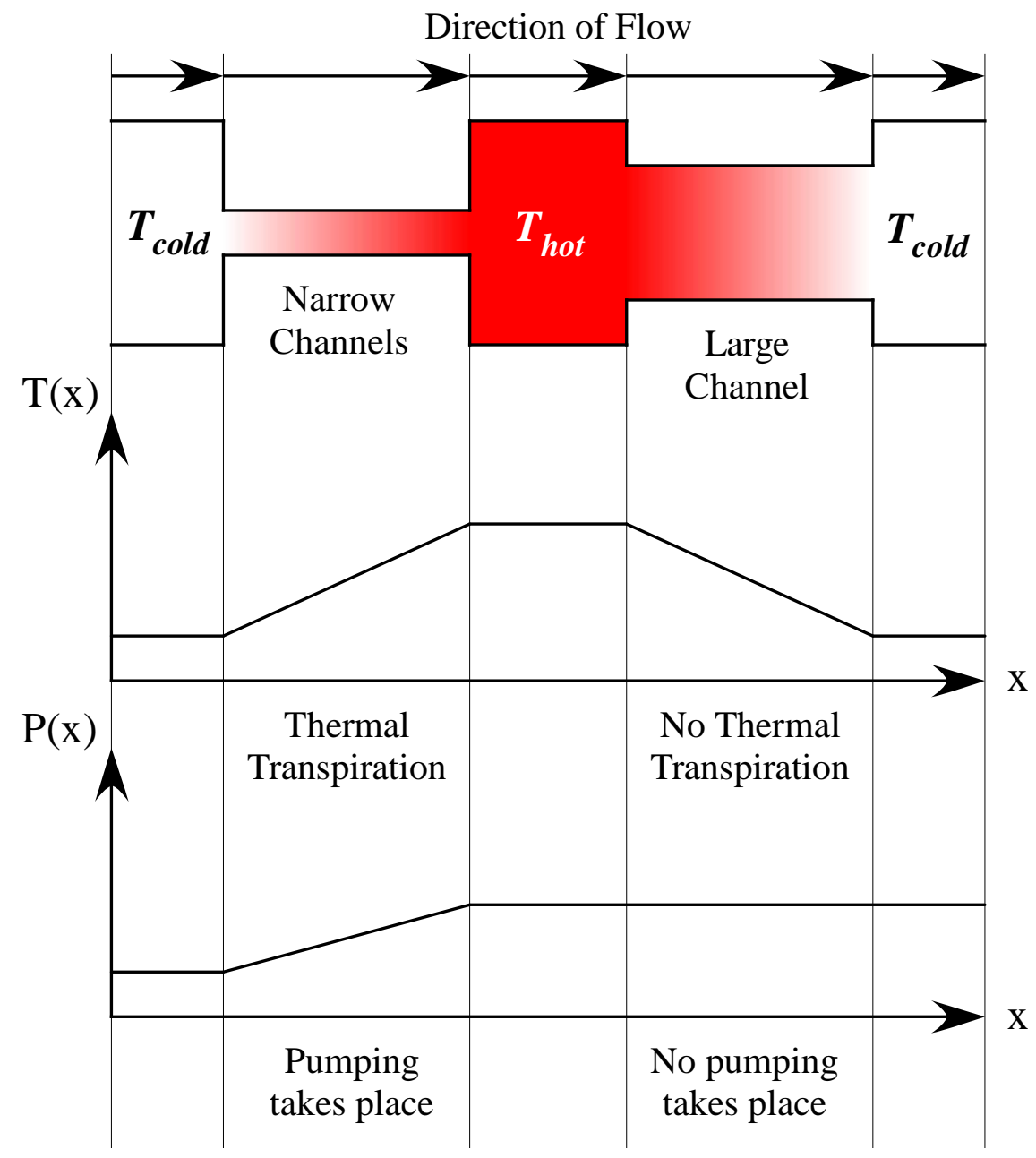

Figure 5. Knudsen Pump design, which may be cascaded to create a greater pressure ratio.

Narrow channels are used to move the gas from the cold to the hot side and then to the large channel where it would be cooled in preparation to enter the next stage. Thermal 
transpiration takes place in the narrow channels; however, the connector section undergoes thermal creep flow in the opposing direction, which contributes to a reduction in efficiency in a multistage pump. It should be noted that that the total efficiency of a multistage pump is generally obtained by multiplying the efficiency of the individual stages. Therefore, any pump design aiming to achieve a maximum efficiency needs to have only one stage.

\subsection{Review of Other Thermal Pumps}

Besides the Knudsen pump other thermal pumps exist, such as accommodation pump and thermomolecular pump [19]. Cryogenic pumps also function based on a thermal gradient, but as opposed to using the thermal gradient to evacuate molecules from one chamber to another the pressure is reduced as the molecules are condensed out [20]. Due to this cryogenic pumps are sometimes referred to as cryotraps. The accommodation uses a smooth wide tube to connect the hot and cold chamber. The heated molecules have a greater tangential momentum accommodation coefficient (TMAC) and travel faster than the cold molecules, resulting in a net flux from the hot to the cold side. The thermomolecular pump works on the principle that scattering of gas molecules from certain surfaces depends on the temperature of the molecules. The hot molecules striking a cold surface have a tendency to scatter away from the normal while cold molecules striking a hot surface have a tendency to scatter toward the normal. This establishes a net flux from the hot to the cold side. 


\subsection{Outline}

The research and discussion herein will be mostly focused on pumps fabricated with well defined channels, although many principles are applicable to pumps with channels made of a porous material. This thesis will focus on the development of the pump efficiency with no losses in chapter 2 and the pump efficiency with energy losses in chapter 3 . The experiment set up and associated calculations are discussed in chapter 4, while simulations of the tested device and an improved design are presented in chapter 5. The conclusions are presented in chapter 6 . 


\section{CHAPTER II}

\section{KNUDSEN PUMP EFFICIENCY WITH NO THERMAL LOSSES}

\subsection{Knudsen Pump Ideal Efficiency though an Aperture}

Previous work by Muntz and others on quantifying efficiency resulted in the development of parameters, which, when optimized, improved pump performance [14]. It was determined that minimizing the energy required per molecule of upflow would reduce the total power consumed, while minimizing the volume per molecule of upflow would reduce the total volume of the pump.

Expanding upon this to determine a more general relation for the ideal efficiency would allow the Knudsen pump to be compared to macro scale pumps. Another benefit of deriving the ideal efficiency, would be knowing the practical limits of the pump's ability to transfer energy from a heat gradient to kinetic energy, in terms of flow rate and/or potential energy, in terms of a developed pressure gradient. This would allow for a greater understanding of the applications for which the pump is best suited.

It is useful to consider a more detailed view of the flux through an aperture whose characteristic dimension is substantially smaller than the mean free path of the gas being pumped. This constraint is equivalent to the assumption of collisionless flow through the aperture. A detailed view is depicted in Figure 6. 


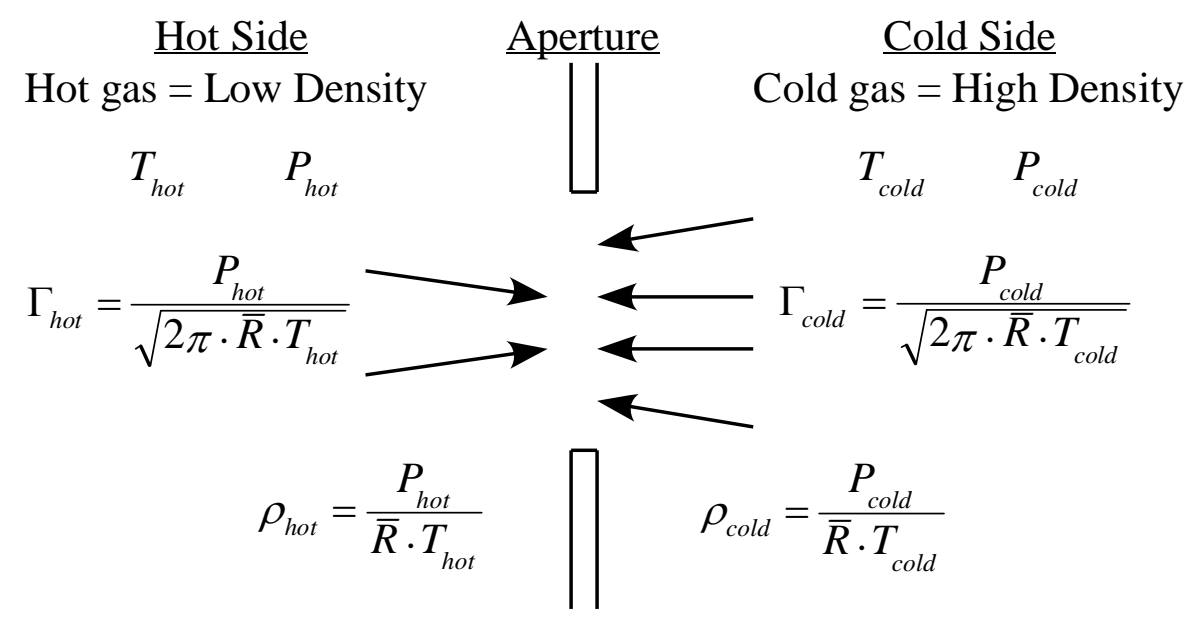

For the pump to function: $\Gamma_{\text {cold }}>\Gamma_{\text {hot }}$ and $\rho_{\text {cold }}>\rho_{\text {hot }}$

Figure 6. Detailed view of the flux through an aperture.

For the pump to function the flux from the cold side, $\Gamma_{\text {cold }}$, must exceed the flux from the hot side, $\Gamma_{h o t}$. Since the density of the gas on each side follows the same trends as the flux, the density of the cold side, $\rho_{\text {cold }}$, must also be greater than the density on the hot side, $\rho_{\text {hot }}$, for the pump to function. Considering these relations, general trends can be obtained, which will improve the functionality and with that increase the efficiency of the pump. Table 2 contains these generalized conditions.

\begin{tabular}{|c|c|c|}
\hline Condition & $\begin{array}{l}\text { Impact } \\
\text { on Flux }\end{array}$ & $\begin{array}{c}\text { Impact on } \\
\text { Efficiency }\end{array}$ \\
\hline$P_{\text {hot }} \uparrow$ & $\Gamma_{\text {hot }} \uparrow$ & $\eta \downarrow$ \\
\hline$P_{\text {cold }} \uparrow$ & $\Gamma_{\text {cold }} \uparrow$ & $\eta \uparrow$ \\
\hline$T_{\text {hot }} \uparrow$ & $\Gamma_{\text {hot }} \downarrow$ & $\eta \uparrow$ \\
\hline$T_{\text {cold }} \downarrow$ & $\Gamma_{\text {cold }} \uparrow$ & $\eta \uparrow$ \\
\hline
\end{tabular}

Table 2. Conditions that impact the efficiency of the pump.

Any equation which attempts to quantify efficiency must follow the above tends. It should also satisfy equation (1), the equilibrium condition. 
The perspective that needs to be taken to optimize the Knudsen pump varies vastly from macro scale pumps, because the main transport phenomenon is effusion, as opposed to bulk fluid movement. Macro scale pumps often receive input power from a rotating shaft and this energy is transferred into useful hydraulic energy, the ratio of which is the efficiency. On the other hand, the Knudsen pump's input power comes from the heating of one side; this may be accomplished in several ways. Energy put into the hot side, in terms of $T_{h o t}$, will be useful only if it is used to decrease $\Gamma_{h o t}$ and with that the gas density on the hot side. Additionally, if the cold side is cooled further, $\Gamma_{\text {cold }}$ increases and so does the efficiency; both scenarios could potentially take place at the same time. As the energy invested in the hot side increases, the molecules from the hot side are able to do more work in terms of expansion. Any equation should therefore capture that the smaller the $\Gamma_{h o t}$ and $\rho_{h o t}$, the larger $T_{\text {hot }}$ is required, the more work the hot side does, and the greater the efficiency of the pump.

For the development of the ideal efficiency, it is useful to consider having two opposing pumps, one on the hot side and the other on the cold side. The more work the hot pump does the fewer molecules will diffuse from the hot side, increasing the efficiency. The work done by each pump is described using

$$
W=P \Delta V
$$

or

$$
W=P \Delta\left(\frac{m}{\rho}\right)
$$

where $P$ is the pressure, $\Delta V$ is the change in volume, $m$ is the mass, and $\rho$ is the density. Power from equation (7) is obtained by deriving the mass with respect to time. Then, if the 
mass flow rate is substituted with density times the volumetric flow rate $(\dot{m}=\rho \dot{V}=\rho A v)$, the following is obtained for power,

$$
\dot{W}=P(A v)
$$

where $\dot{W}$ is power, $P$ is the pressure, $A$ is the cross-sectional area, and $v$ is the velocity. The velocity is obtained by dividing the flux by the density. Substituting the velocity into equation (8) results in

$$
\dot{W}=P\left(A \frac{\Gamma}{\rho}\right)
$$

where $\Gamma$ is the flux through the aperture and $\rho$ is the density of the gas. As mentioned previously, each side of the aperture functions as its own independent pump that does work opposing the other pump. Useful power is obtained using

$$
\dot{W}_{\text {useful }}=\dot{W}_{\text {hot }}-\dot{W}_{\text {cold }}
$$

where the subscripts indicate which side of the pump generates the power. To understand the signs associated with the powers in equation (10) it is helpful to consider Figure 7.

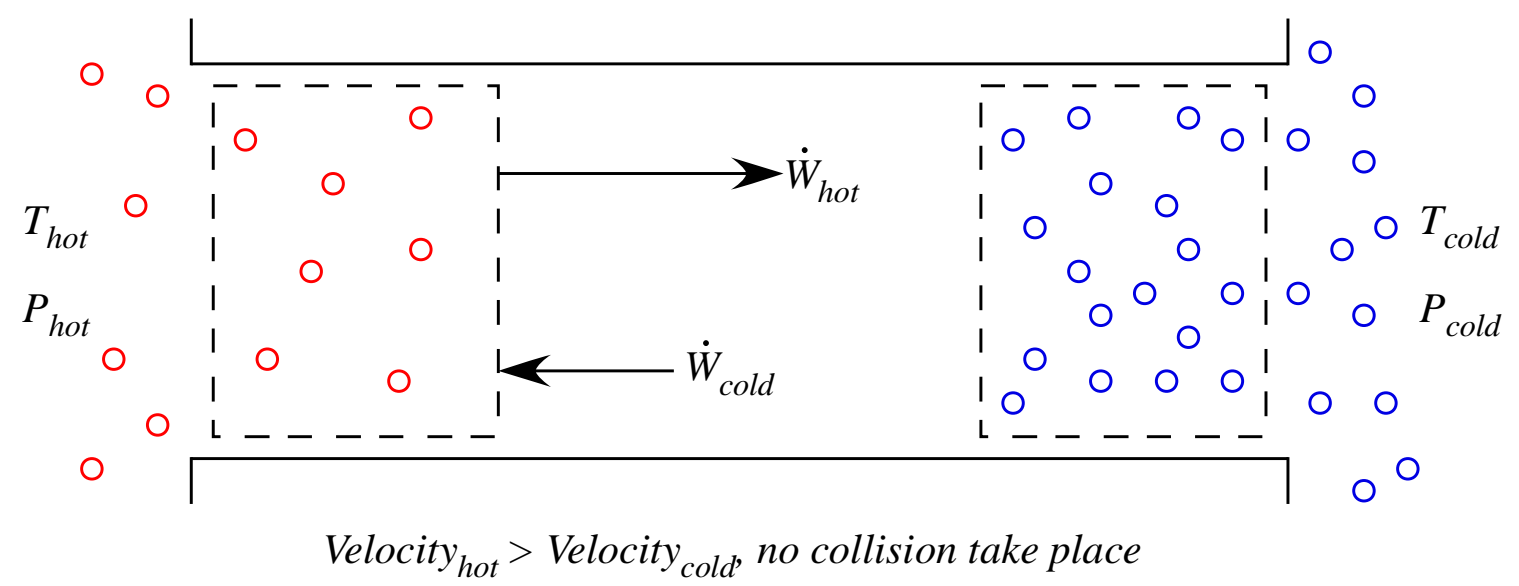

Figure 7. Enlarged view of aperture for power consideration. 
It should be noted that, although a short channel is shown in Figure 7, this is only for clarity; the aperture assumption is still held. Since power is invested in the hot side in terms of heat transfer, the power exerted by and on the hot side is of interest. Using the steam engine convention for work and energy, both the work output and power input are considered positive.

Efficiency, in general, is defined as:

$$
\eta_{\text {ideal }}=\frac{\frac{\dot{W}_{\text {useful }}}{\dot{m}}}{\frac{\dot{W}_{\text {input }}}{\dot{m}}}
$$

where, for the Knudsen pump, $\dot{W}_{\text {input }}$ can be considered to be electric power. The input power may also come from solar or geothermal energy as well as waste heat; these would however change the development of the efficiency. Determining the maximum efficiency of the pump requires the assumption that all the energy that is invested in the hot side goes to heating of the gases and that none is lost to the fixture. It should be noted that both gas fluxes must be heated. The hot flux is heated before it crosses the aperture and the cold one gets heated after it has crossed the aperture. Assuming that the temperature at which the hot gas starts is the same as the cold temperature, the change in temperature associated with heating both the gas flows is the same. The input energy for a Knudsen pump heated via electrical energy is calculated using

$$
\dot{W}_{\text {useful }}=I V=\dot{m}_{\text {hot }} c_{p} \Delta T+\dot{m}_{\text {cold }} c_{p} \Delta T+\Delta T G
$$


where $I$ is the current through the heater, $V$ is the voltage applied across the heater, $\dot{m}_{h o t}$ indicates the mass flow from the hot side, $\dot{m}_{\text {cold }}$ indicates the mass flow from the cold side, $c_{p}$ is the specific heat per unit mass, and $G$ is a term used to lump together the energy losses to the environment; this term is proportional to $\Delta T$, assuming the losses are dominated by thermal conduction, and is geometry specific. No energy losses $(G=0)$ corresponds to the ideal case. As shown previously, the mass flow rate is obtained by multiplying the flux by the cross-sectional area of the aperture.

The ideal efficiency model is obtained by combining equations (10) and (11) and dividing each power with its associated mass flow rate. The interpretation of each term is the power exerted by the mass flow or the work exerted per unit mass. Considering this, the ideal efficiency is calculated using

$$
\eta_{\text {ideal }}=\frac{\frac{\dot{W}_{\text {hot }}}{\dot{m}_{\text {hot }}}-\frac{\dot{W}_{\text {cold }}}{\dot{m}_{\text {cold }}}}{\frac{\dot{W}_{\text {input }}}{\dot{m}_{\text {net }}}}
$$

where $\dot{m}_{\text {net }}$ is the net mass flow rate $\left(\dot{m}_{\text {net }}=\dot{m}_{\text {cold }}-\dot{m}_{\text {hot }}\right)$. After equations (8) and (11) are substituted in equation (13), the following result is obtained:

$$
\eta_{\text {ideal }}=\frac{\frac{P_{h o t}\left(A \frac{\Gamma_{h o t}}{\rho_{h o t}}\right)}{\dot{m}_{\text {hot }}}-\frac{P_{\text {cold }}\left(A \frac{\Gamma_{\text {cold }}}{\rho_{\text {cold }}}\right)}{\frac{A C_{p} \Delta T\left(\Gamma_{\text {hot }}+\Gamma_{\text {cold }}\right)}{\dot{m}_{\text {net }}}}}{\dot{m}_{\text {cold }}}
$$

After further substitution for the density and the mass flow rates, equation (14) becomes 


$$
\eta_{\text {ideal }}=\frac{\left.\frac{P_{h o t}\left(A \frac{\Gamma_{\text {hot }}}{\frac{P_{h o t}}{\bar{R} T_{\text {hot }}}}\right)}{A \Gamma_{\text {hot }}}-\frac{P_{\text {cold }}\left(A \frac{\Gamma_{\text {cold }}}{P_{\text {cold }}}\right.}{\bar{R} T_{\text {cold }}}\right)}{\frac{A \Gamma_{p} \Delta T\left(\Gamma_{\text {cold }}+\Gamma_{\text {cold }}\right)}{A\left(\Gamma_{\text {cold }}-\Gamma_{\text {hot }}\right)}},
$$

simplifications yield

$$
\eta_{\text {ideal }}=\frac{\bar{R}}{c_{p}}\left(\frac{\Gamma_{\text {cold }}-\Gamma_{\text {hot }}}{\Gamma_{\text {hot }}+\Gamma_{\text {cold }}}\right)
$$

Substituting the equation for flux and simplifying, results in

$$
\eta_{\text {ideal }}=\frac{\bar{R}}{c_{p}}\left(\frac{\frac{P_{\text {cold }}}{T_{\text {cold }}^{1 / 2}}-\frac{P_{\text {hot }}}{T_{\text {hot }}^{1 / 2}}}{\frac{P_{\text {hot }}}{T_{\text {hot }}^{1 / 2}}+\frac{P_{\text {cold }}}{T_{\text {cold }}^{1 / 2}}}\right) .
$$

Equation (17) is rearranged to yield the final result for ideal efficiency of the Knudsen pump, assuming collisionless flow through an aperture,

$$
\eta_{\text {ideal }}=\frac{R}{C_{p}}\left(\frac{\sqrt{\frac{T_{\text {hot }}}{T_{\text {cold }}}}-\frac{P_{\text {hot }}}{P_{\text {cold }}}}{\frac{P_{\text {hot }}}{P_{\text {cold }}}+\sqrt{\frac{T_{\text {hot }}}{T_{\text {cold }}}}}\right)
$$

where $R$ is the universal gas constant, $C_{p}$ is the specific heat; the temperatures and pressures are indicated by subscript. It should be noted that $\frac{\bar{R}}{c_{p}}=\frac{R}{C_{p}}$ is used in the simplification.

The ideal efficiency equation contains some necessary behavior that has not been imposed on it during derivation, but that results as a byproduct. This behavior includes that the equation will never exceed one, as the $\frac{R}{C_{p}}$ ratio, by definition, is always less than one 
and the temperature ratio and pressure ratios also cannot exceed one. The equation also results in zero efficiency when the system has reached its equilibrium condition $\left(P_{\text {hot }}=P_{\text {cold }} \sqrt{\frac{T_{h o t}}{T_{\text {cold }}}}\right)$. It should be noted that since the specific heat and gas constant are included in equation (18), different gases will have different pumping efficiencies.

The development of this equation can only be justified if the trends detailed in Table 1 are followed. Demonstrating this will be done through a series of figures detailing the trends of the efficiency, as the parameters are varied for air. The surface in Figure 8 is generated by assuming a pressure ratio of one in the ideal efficiency equation and by varying $T_{\text {cold }}$ from nearly $0 \mathrm{~K}$ to $300 \mathrm{~K}$ and $T_{\text {hot }}$ from $300 \mathrm{~K}$ to $1,300 \mathrm{~K}$.

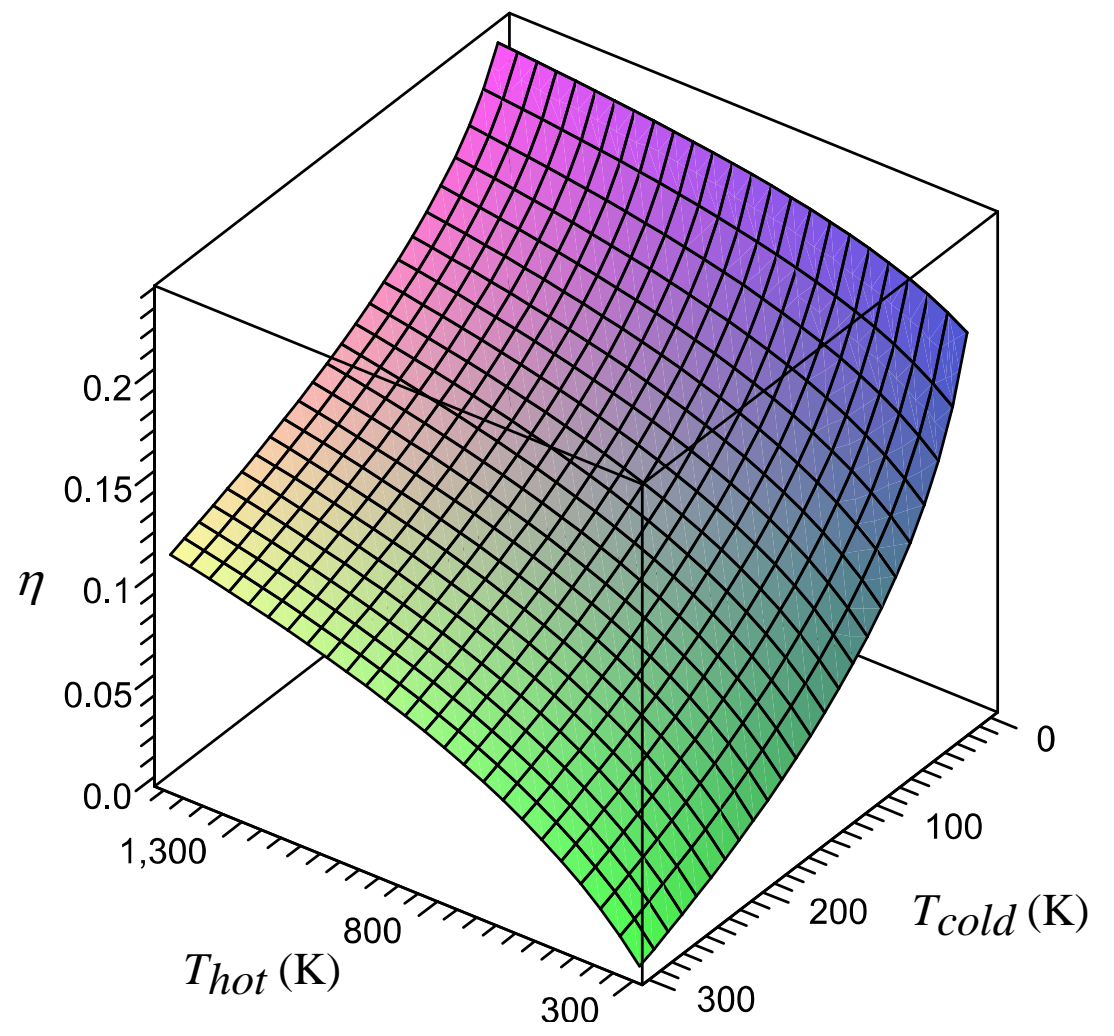

Figure 8. Surface of ideal efficiency as a function of $T_{\text {cold }}$ and $T_{\text {hot }}$, using the constraint

$$
P_{h o t} / P_{\text {cold }}=1
$$


It should be noted that when the ratio of $\sqrt{T_{h o t}}$ to $\sqrt{T_{\text {cold }}}$ equals one, the efficiency drops to zero, because this ratio equals the ratio of $P_{\text {hot }}$ to $P_{\text {cold }}$. This is a necessary condition for zero efficiency to be reached, since equilibrium is established. A useful perspective is to plot the efficiency as a function of the temperature ratio, $T_{r}=\frac{T_{h o t}}{T_{\text {cold }}}$, for a pressure ratio of one (Figure 9).

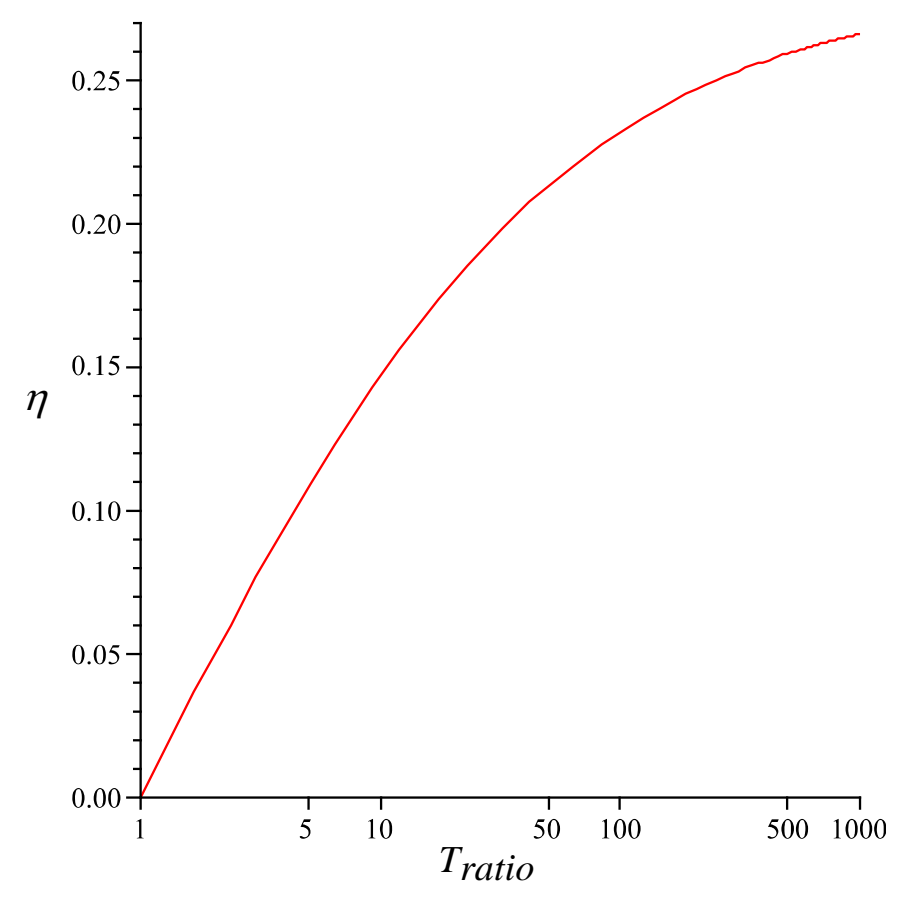

Figure 9. Plot of efficiency vs. temperature ratio for air.

The efficiency, on a linear plot, asymptotically approaches $28.36 \%$ as the temperature ratio approaches infinity. However, the very large temperature ratios cannot be easily achieved unless $T_{\text {cold }}$ is drastically lowered below one Kelvin. Figure 8 and 9 both indicate that the efficiency increases as $T_{\text {hot }}$ increases or $T_{\text {cold }}$ decreases, in agreement with Table 1 . The other two required trends state that as $P_{h o t}$ increases, the efficiency will decrease and that as $P_{\text {cold }}$ increases, the efficiency will increase; Figures 10 and 11 demonstrate this, respectively. 


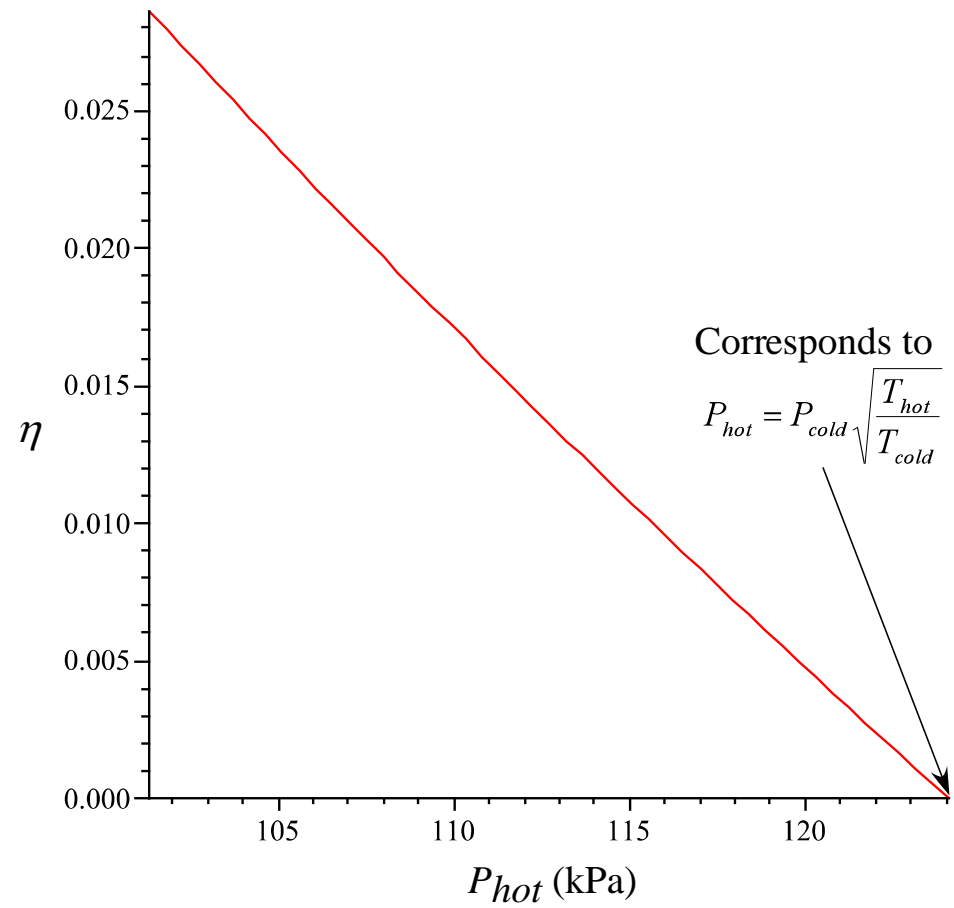

Figure 10. Pressure on the hot side in Pascals versus efficiency for a temperature ratio of 1.5 and atmospheric pressure on the cold side.

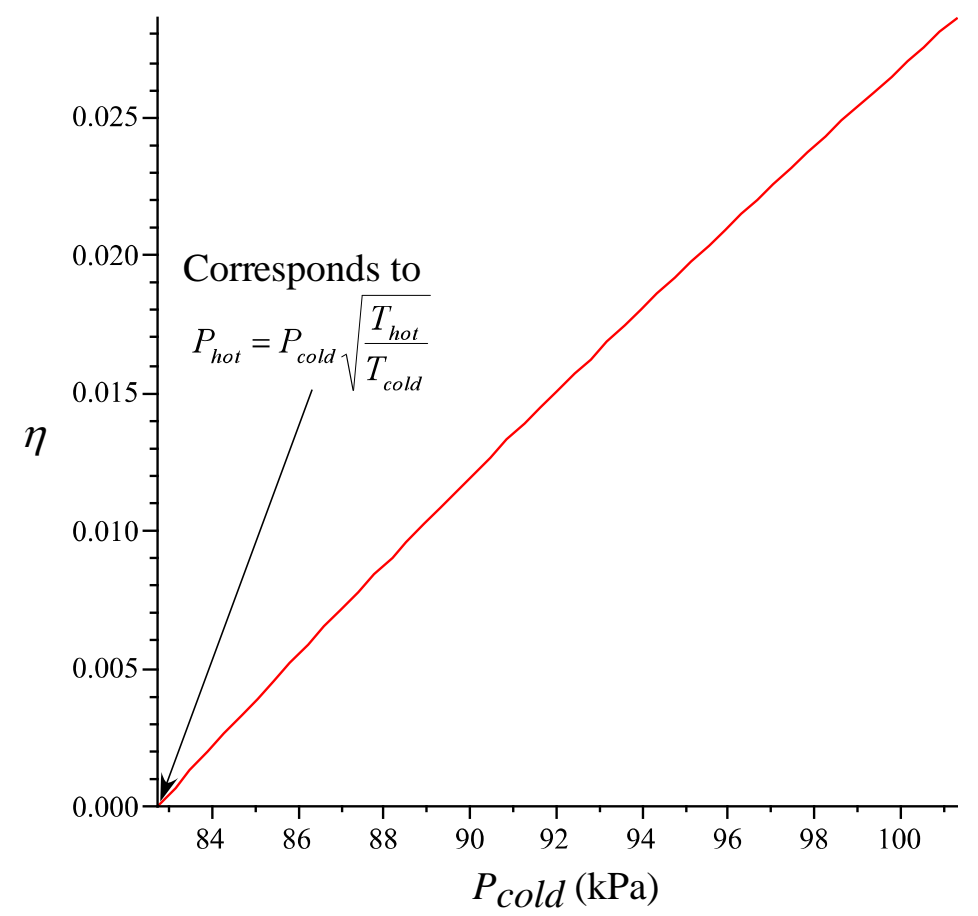

Figure 11.Pressure on the cold side in Pascals versus efficiency for a temperature ratio of 1.5 and atmospheric pressure on the hot side. 
The lowest pressure in Figure 11 is constrained in such a manner as to be consistent with the maximum pressure ratio that can be generated by a specified temperature gradient.

Although the derived ideal efficiency of the Knudsen pump is based on the efficiency definition of macro scale pumps, its behavior varies due to effusion, which is the main form of mass transport.

\subsection{Efficiency for Different Gases}

The resulting equation for ideal efficiency of a Knudsen pump having collisionless thermal transpiration based effusion through an aperture indicates that gases with different specific heats will have varying pumping efficiencies. The efficiencies of different gases versus the temperature ratio are plotted in Figure (12) versus the temperature ratio and with a pressure ratio of one.

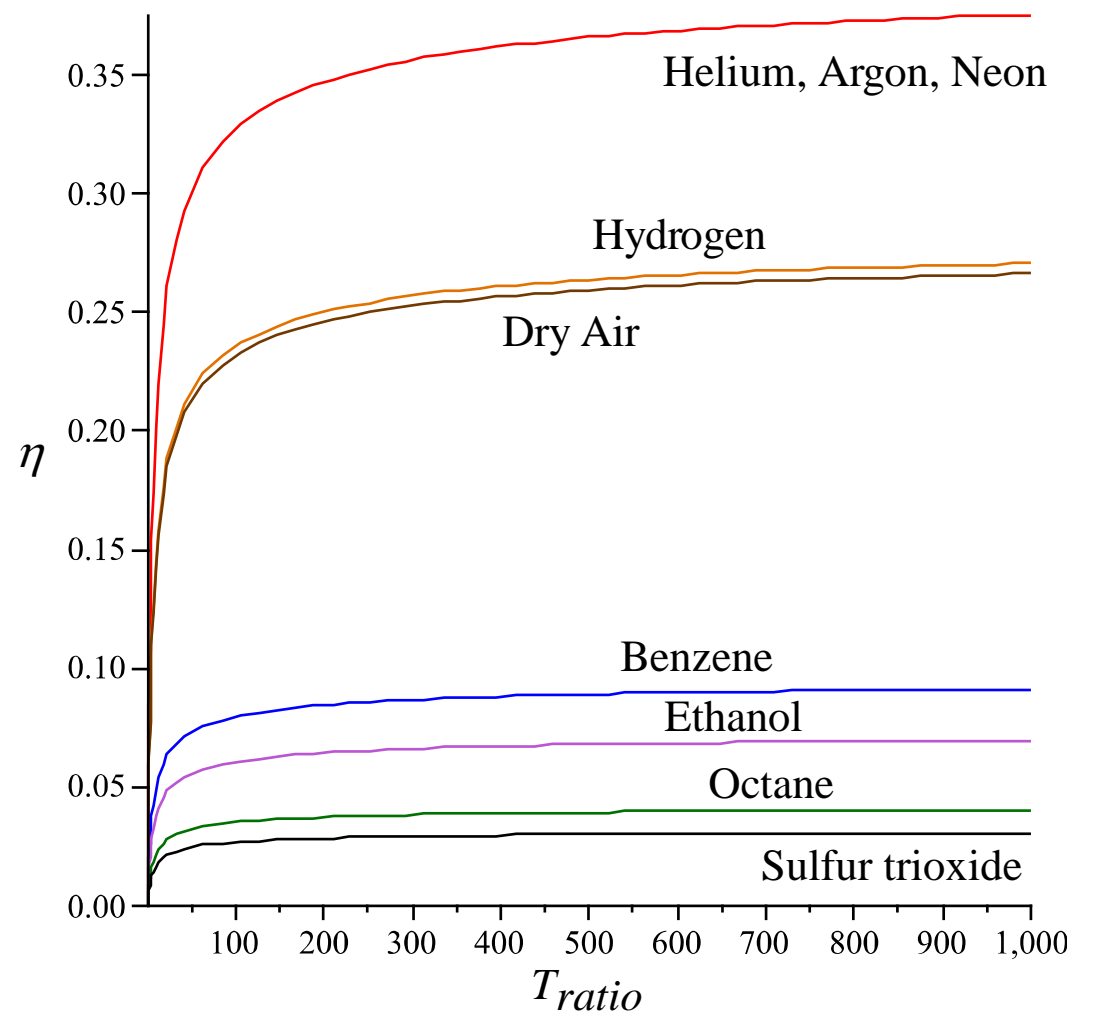

Figure 12. Efficiencies of selected gases plotted versus the temperature ratio. 
The maximum efficiencies of selected gases are shown in Table 3.

\begin{tabular}{|c|c|}
\hline Gas & Maximum Efficiency \\
\hline \hline Helium, Argon, Neon & $40.00 \%$ \\
\hline Hydrogen & $28.84 \%$ \\
\hline Dry Air & $28.36 \%$ \\
\hline Benzene & $9.75 \%$ \\
\hline Ethanol & $7.44 \%$ \\
\hline Octane & $4.32 \%$ \\
\hline Sulfur Trioxide & $3.29 \%$ \\
\hline
\end{tabular}

Table 3. Maximum efficiencies of selected gases.

This data suggest that the Knudsen pump may have applications in sorting gases. For instance, the Knudsen pump may be powered by waste heat from smoke stacks to filter Sulfur Trioxide, a key component in acid rain, from the exhaust. 


\section{CHAPTER III}

\section{KNUDSEN PUMP EFFICIENCY INCLUDING THERMAL LOSSES}

\subsection{Accounting for Losses in Efficiency}

The versatility of the previously developed efficiency equation can be greatly extended if it can be used to predict efficiencies of fabricated Knudsen pumps. The efficiency equation is expanded by quantifying the energy losses associated with the increase in channel length and by taking the geometry of the pump into consideration. Again, it is useful to consider two opposing pumps. However, as opposed to using the flux (equation 2) to quantify the mass flow through the aperture, the conductance of a channel of arbitrary crosssection will be used. Knudsen [21] was the first to use a quantity for pipe impedance analogous to electrical resistance; later this was modified by Dushman [22] to conductance. Conductance is the inverse of resistance.

There are a numerous analogies that can be constructed between a fluid and an electrical system. The analogy used here defines throughput, $\dot{Q}$, traditionally used to quantify a gas flow rate in terms of pressure-volume units, as

$$
\dot{Q}=\frac{d}{d t}(P V)
$$

where the throughput is equivalent to power, $P$ is the pressure and $V$ is the volume. If only volume varies with time, $\frac{d V}{d t}$ is equivalent to conductance, defined as 


$$
C=\frac{\dot{Q}}{\Delta P}
$$

where $\Delta P$ is the pressure change across the channel. The comparison between the analogous fluid system used and an equivalent electrical system is made in Table 4.

\begin{tabular}{|c|c|}
\hline Electrical Quantity & Fluid Analogy \\
\hline \hline Electrical Potential & Pressure Difference \\
\hline Current & Throughput \\
\hline Conductance & Fluid Conductance \\
\hline
\end{tabular}

Table 4. Analogous fluid system compared to electrical system.

Considering conductance as defined in equation (20), allows the pump speeds and the associated piping conductance to be summed as follows

$$
\frac{1}{S_{n e t}}=\frac{1}{S_{\text {pmup }}}+\frac{1}{C_{p i p e}}
$$

where $S_{n e t}$ is the net system volumetric flow rate, $S_{\text {pump }}$ is the pump speed and $C_{\text {pipe }}$ is the conductance of the piping system. Since the Knudsen pump, as explained, above is a channel with a thermal gradient the conductance of the channel is used instead of the pump speed. The conductance for a short channel is then defined as

$$
\frac{1}{C_{n e t}}=\frac{1}{C_{m l}}+\frac{1}{C_{a}}
$$

where $C_{n e t}$ is the net conductance, $C_{m l}$ is the conductance of a long channel and $C_{a}$ is the conductance of an aperture. The general conductance equation for long channels was derived in 1910 by Smoluchowski [23] and found to be

$$
C_{m l}=\frac{v_{a}}{8 l} \int_{s} \int_{-\pi / 2}^{\pi / 2} \frac{1}{2} \rho \cos \theta d \theta d s
$$


where $v_{a}$ is the mean thermal velocity of the molecules, $l$ is the length of the channel, and $\rho$ is the chord making an angle $\theta$ with the normal to the perimeter $s$ [12]. The conductance of an aperture is

$$
C_{a}=A \sqrt{\frac{R T}{2 \pi M}}
$$

where $A$ is the cross-sectional area, $R$ is the universal gas constant, $T$ is the temperature, and $M$ is the molar mass of the gas being pumped.

Assuming the Knudsen pump has long channels implies that the flow resistance of a channel, $\frac{1}{C_{m l}}$, is much greater than the flow resistance of an aperture, $\frac{1}{C_{a}}$. For manipulation in further derivations it is useful to define the general conductance for long channels as follows

$$
C=\frac{v_{a}}{8 l} C^{\prime}
$$

where $C^{\prime}$ is defined as

$$
C^{\prime}=\int_{s} \int_{-\pi / 2}^{\pi / 2} \frac{1}{2} \rho \cos \theta d \theta d s
$$

This allows further derivation without committing to a particular cross-section. The mean thermal velocity is defined as

$$
v_{a}=\sqrt{\frac{8 R T}{\pi M}}
$$

where $R$ is the universal gas constant, $T$ is the temperature, and $M$ is the molar mass. At this point it is useful to consider the mass flow from the hot side and the cold side as two opposing pumps. The efficiency is similar to equation (13) with the exception that $\dot{W}_{h o t}$ and 
$\dot{W}_{\text {cold }}$ are replaced by $\dot{Q}_{\text {hot }}$ and $\dot{Q}_{\text {cold }}$, respectively. The efficiency of the pump with losses has the following form

$$
\eta=\frac{\frac{\dot{Q}_{\text {hot }}}{\dot{m}_{\text {hot }}-\frac{\dot{Q}_{\text {cold }}}{\dot{m}_{\text {cold }}}}}{\frac{\dot{W}_{\text {input }}}{\dot{m}_{\text {total }}}}
$$

where $\dot{Q}$ indicates the power exerted by the gas, $\dot{m}$ the mass flow of the gas, and $\dot{W}_{\text {input }}$ the power input. The subscripts hot and cold indicate the side of the pump. The throughput is calculated using

$$
\dot{Q}=P \sqrt{\frac{R T}{2 \pi M}} \frac{C^{\prime}}{2 l}=P \frac{\dot{m}}{\rho}
$$

It should be noted that differential pressure in equation (29) has been replaced with the pressure at one of the sides of the pumps. After substituting density, and equations (12) and (29) into equation (28), the equation for efficiency is

$$
\eta=\frac{R}{C_{p}}\left(\frac{\dot{m}_{\text {cold }}-\dot{m}_{h o t}}{\dot{m}_{\text {hot }}+\dot{m}_{\text {cold }}+\frac{M}{C_{p}} G}\right) .
$$

It should be noted that $\mathrm{G}$ is not assumed to be zero as it is used to quantify losses. The mass flow rate is calculated using

$$
\dot{m}=\rho C_{m l}
$$

which becomes

$$
\dot{m}=\frac{C^{\prime}}{2 l} \frac{P}{\sqrt{2 \pi \bar{R} T}}=\frac{C^{\prime}}{2 l} \Gamma
$$


after substitutions. After substitution of equation (32) into equation (30), the efficiency becomes

$$
\eta=\frac{R}{C_{p}}\left(\frac{\Gamma_{c o l d}-\Gamma_{h o t}}{\Gamma_{h o t}+\Gamma_{c o l d}+\frac{2 l}{C^{\prime}} \frac{M}{C_{p}} G}\right)
$$

Once equation (2) is substituted for the flux above, the following results

$$
\eta=\frac{\bar{R}}{c_{p}}\left(\frac{\frac{P_{\text {cold }}}{T_{\text {cold }}^{1 / 2}}-\frac{P_{\text {hot }}}{T_{\text {hot }}^{1 / 2}}}{\frac{P_{\text {hot }}}{T_{\text {hot }}^{1 / 2}}+\frac{P_{\text {cold }}}{T_{\text {cold }}^{1 / 2}}+(\sqrt{2 \pi R})\left(\frac{2 l}{C^{\prime}} \frac{M}{C_{p}}\right) G}\right)
$$

after simplification the final result is obtained

$$
\eta=\frac{R}{C_{p}}\left(\frac{\sqrt{\frac{T_{h o t}}{T_{\text {cold }}}}-\frac{P_{\text {hot }}}{P_{\text {cold }}}}{\frac{P_{\text {hot }}}{P_{\text {cold }}}+\sqrt{\frac{T_{h o t}}{T_{\text {cold }}}}+\left(\sqrt{2 \pi \bar{R} T_{\text {hot }}} \frac{2 l}{C^{\prime}} \frac{M}{C_{p}} \frac{G}{P_{\text {cold }}}\right)}\right)
$$

The assumption, as mentioned previously, is that the Knudsen pump has long channels with collisionless flow. The developed equation follows the trends required in Table 1 to be considered valid.

\subsection{Accounting for Geometry Specific Losses in Efficiency}

Quantifying the thermal losses, in terms of $G$, requires assumptions about the channel geometry and heating method to be made. Since the heating of the gas molecules diffusing from the hot side is desirable, the losses can be quantified as the unintended heat conducted along the channel. To better understand the heating of the channel and the associated heat flows requires a detailed view of Figure 13. 


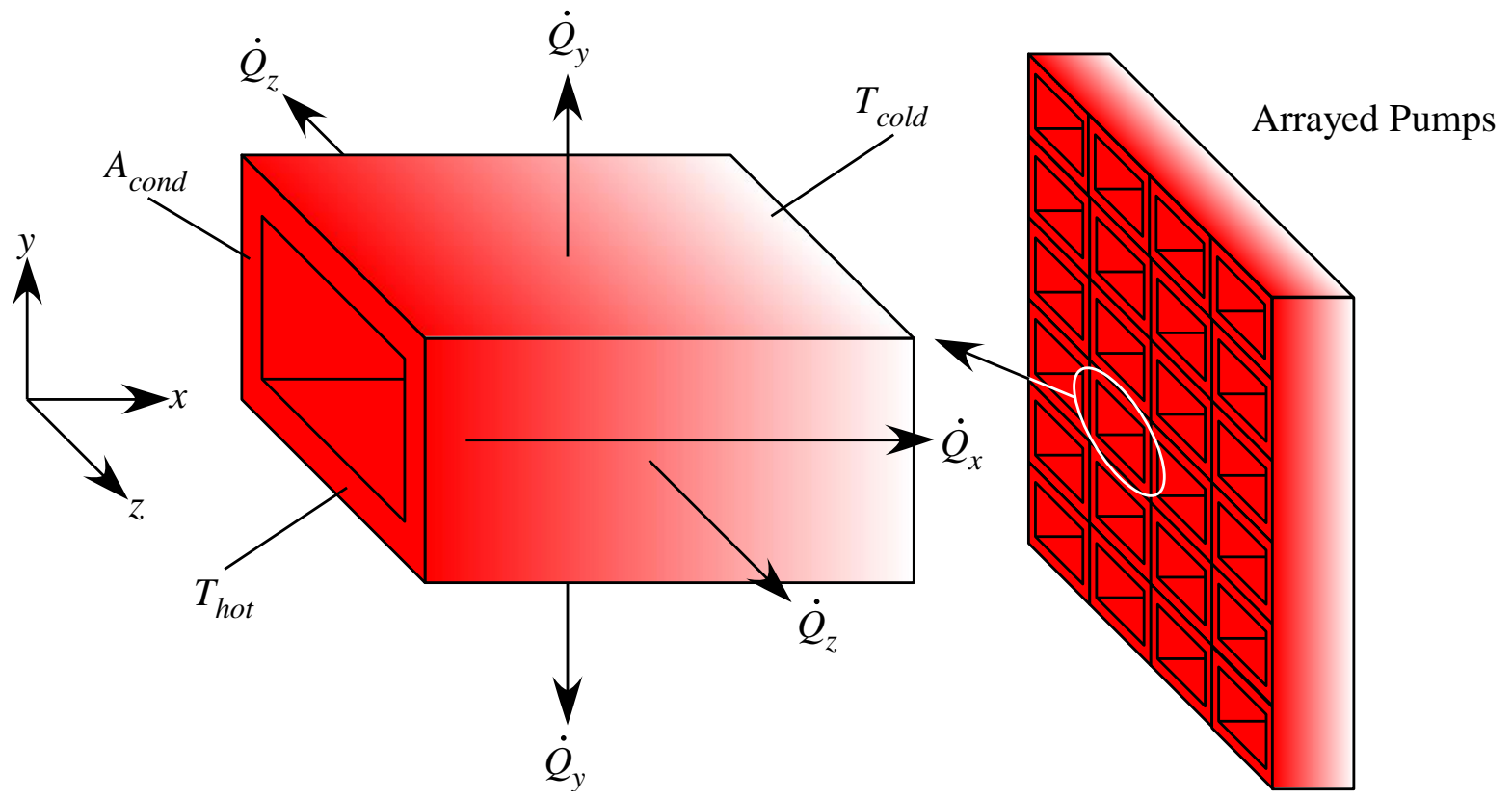

Figure 13. Knudsen pump with a rectangular channel heated to temperature and the losses associated with this.

Although a rectangular channel is shown, the derivation is independent of channel crosssection. The steady state heat flow through the channel wall is

$$
\dot{Q}_{x}=A_{\text {cond }} k \frac{\Delta T}{l}
$$

where $k$ is the material's heat conductivity and $A_{\text {cond }}$ is the cross-sectional area of the channel wall. The heat transfer perpendicular to the channel walls is lost to the surroundings and can be very difficult to quantify; however, if the pump is arrayed into a membrane these heat transfer rates are nearly zero $\left(\dot{Q}_{y}=0, \dot{Q}_{z}=0\right)$, ignoring edge effects. With the previous assumption that the losses equal $\Delta T G$ and using equation (36), the following results

$$
G=A_{\text {cond }} \frac{k}{l}
$$

Substitution of equation (37) into equation (35) results in 


$$
\eta=\frac{R}{C_{p}}\left(\frac{\sqrt{\frac{T_{h o t}}{T_{\text {cold }}}-\frac{P_{\text {hot }}}{P_{\text {cold }}}}}{\frac{P_{\text {hot }}}{P_{\text {cold }}}+\sqrt{\frac{T_{\text {hot }}}{T_{\text {cold }}}}+\left(\sqrt{2 \pi \bar{R} T_{\text {hot }}} \frac{2}{C^{\prime}} \frac{M}{C_{p}} \frac{A_{\text {cond }} k}{P_{\text {cold }}}\right)}\right) .
$$

Equation (38) is the efficiency with the losses accounted for and the assumption that the Knudsen pump has a long channel with collisionless flow. The cross-section independence has been maintained by not specifying $C^{\prime}$ and $A_{\text {cond }}$. Before an illustrative example can be given both of these values have to be quantified for a specific geometry.

The conductance for the channel may be computed using

$$
C=C_{a} \alpha
$$

where $C_{a}$ is the conductance of an aperture and $\alpha$ is the cross-section dependent transmission probability. The $C^{\prime}$ is obtained by taking $\alpha$ values that have been computed in the literature, such as [12], substituting them in equation (39), and reforming this equation in the following form

$$
C=\left(\frac{1}{2 l} \sqrt{\frac{\bar{R} T}{2 \pi}}\right) C^{\prime} .
$$

This is done for the circular and rectangular cross-sections below. For the circular crosssection, the transmission probability is [12]

$$
\alpha_{\text {circle }}=\frac{4 d}{3 l}
$$

where $d$ is the diameter of the channel and $l$ is its length. Substituting equations (24) and (41) into equation (39) yields

$$
C=\left(\frac{1}{2 l} \sqrt{\frac{\bar{R} T}{2 \pi}}\right)\left(\frac{2}{3} \pi d^{3}\right) .
$$


Comparing equations (40) and (42), $C^{\prime}$ is found to be

$$
C_{\text {circle }}^{\prime}=\frac{2}{3} \pi d^{3}
$$

The transmission probability for a rectangular cross-section is [12]

$$
\alpha_{\text {rect }}=\frac{16}{3 \pi^{\frac{3}{2}}} \frac{a}{l} \ln \left(4 \frac{b}{a}+\frac{3}{4} \frac{a}{b}\right)
$$

where $a$ is the height of the channel, $b$ is its width, and $l$ is its length. After substituting equation (23) and (44) into equation (38) and simplifying, the following $C^{\prime}$ is obtained

$$
C_{r e c t}^{\prime}=\frac{32}{3 \pi^{\frac{3}{2}}} a^{2} b \ln \left(4 \frac{b}{a}+\frac{3}{4} \frac{a}{b}\right) .
$$

If the following approximation for $\alpha_{\text {rect }}$ is used

$$
\alpha_{\text {rect }} \approx \frac{a}{l}\left(\ln \left(\frac{2 l}{a}\right)-\frac{1}{2}\right),
$$

which is only valid if the channel length is much greater than the height and the width is much greater than the height and the length $(b>>l>>a)$, then $C^{\prime}$ may be simplified to:

$$
C_{r e c t}^{\prime} \approx 2 a^{2} b\left(\ln \left(\frac{2 l}{a}\right)-\frac{1}{2}\right) .
$$

It should be noted that the efficiency with losses, equation (37), does not depend on length and neither do $C_{\text {circle }}^{\prime}$ or $C_{\text {rect }}^{\prime}$. The explanation for the lack of dependence of the efficiency on length is explained by considering that an increased length decreases the mass flow, but the energy required to heat this mass flow is also reduced. In regards to the losses in equation (38), the conductance and the power required to maintain the difference in temperature decrease as the channel length increases. Since the ratio of these two values is considered, the length is divided by itself and cancels out. 


\subsection{Illustrative Example of Efficiency}

The impact of the losses on the efficiency of the Knudsen pump, equation (38), can be demonstrated using an example. For this example a Knudsen pump with a wide channel, $50 \mathrm{~nm}$ by $0.1 \mathrm{~mm}$, of considerable length is used. The length, if sufficiently long such that

$\left(\frac{1}{C_{m l}}>\frac{1}{C_{a}}\right), C_{a}$ will drop out of the efficiency equation. The height of the channel is such that mostly collisionless flow takes place. The channel wall thickness is $0.5 \mu \mathrm{m}$. Following the obtained trends from the previous chapter the hot and cold pressures are the same as the atmospheric pressure and the hot temperature is $450 \mathrm{~K}$ while the cold temperature is $300 \mathrm{~K}$. These parameters have been chosen because pumps of similar parameters are currently under experimental investigation. The pumps are arrayed and are perpendicular to a glass wafer, having a thermal conductivity of $1.1 \mathrm{Wm}^{-1} \mathrm{~K}^{-1}$. These values are substituted in equation (37)

$$
\eta=\frac{8.314 \frac{\mathrm{J}}{\mathrm{K} \cdot \mathrm{mol}}}{29.19 \frac{\mathrm{J}}{\mathrm{K} \cdot \mathrm{mol}}}\left(\frac{\sqrt{\frac{450 \mathrm{~K}}{300 \mathrm{~K}}}-\frac{101325 \mathrm{~Pa}}{101325 \mathrm{~Pa}}}{\frac{101325 \mathrm{~Pa}}{101325 \mathrm{~Pa}}+\sqrt{\frac{450 \mathrm{~K}}{300 \mathrm{~K}}}+\left(\sqrt{2 \pi \cdot 287.05 \frac{\mathrm{J}}{\mathrm{kg} \cdot \mathrm{K}} 450 \mathrm{~K}} \frac{2}{5.4067 \cdot 10^{-17} \mathrm{~m}^{3}} \frac{1}{1012 \mathrm{~J} / \mathrm{kg} \cdot \mathrm{K}} \frac{4.0162 \cdot 10^{-9} \mathrm{~m}^{2} \cdot 1.1 \mathrm{~W} / \mathrm{m} \cdot \mathrm{K}}{101325 \mathrm{~Pa}}\right)}\right) .
$$

The result is that with the thermal conduction losses, efficiency is $0.00445 \%$, while without the losses the efficiency for this low temperature ratio case is $2.87730 \%$. The key result to note is that the gas needs to be heated to a very high temperature and that thermal losses through the fixture has a devastating effect on the overall efficiency.

Using these values for the variables in the efficiency equation, Figure 14 shows the efficiency as a function of $T_{h o t}$. As $T_{h o t}$ approaches infinity efficiency approaches $0.023 \%$. 


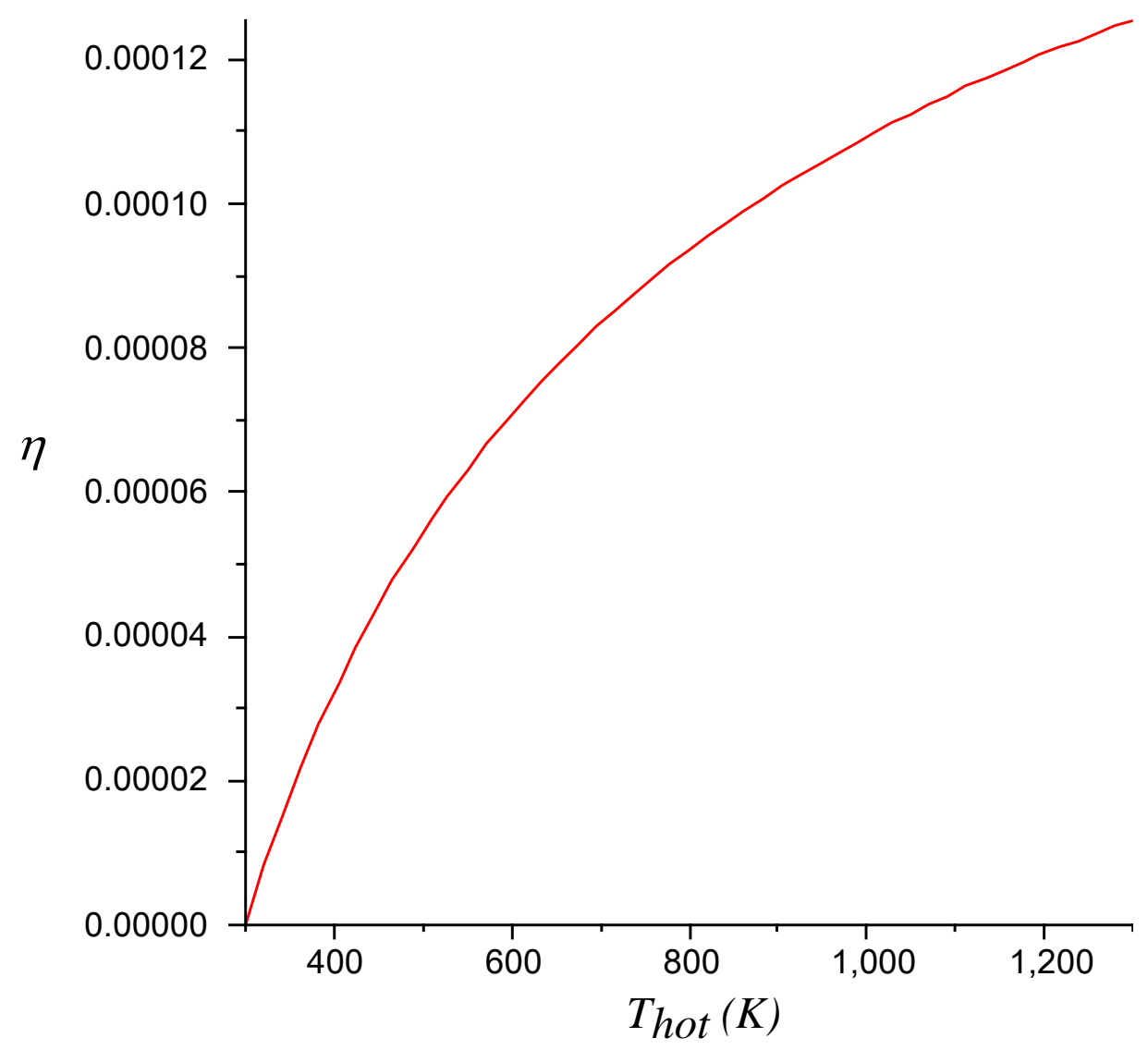

Figure 14. Efficiency from the illustrative example as a function of the temperature on the hot side. 


\section{CHAPTER IV \\ EXPERIMENTAL RESULTS}

\subsection{Test Setup}

The purpose of the experiments was to test the pressure ratios the MEMS fabricated Knudsen pumps were able to develop, to infer the height, and to estimate mass flow rate. The goal of the setup is to achieve minimal dead volume, because low flow rates are expected. The height of one end of the channel could be measured using a scanning electron microscope (SEM); however, this may not be indicative of the effective channel height throughout the channel length. In brief, the experimental setup consists of a closed chamber and pressure sensor on the cold side of the pump and a pressure sensor measuring the hot pressure. The hot side is open to the ambient air. The experimental setup is shown in Figure 15. 


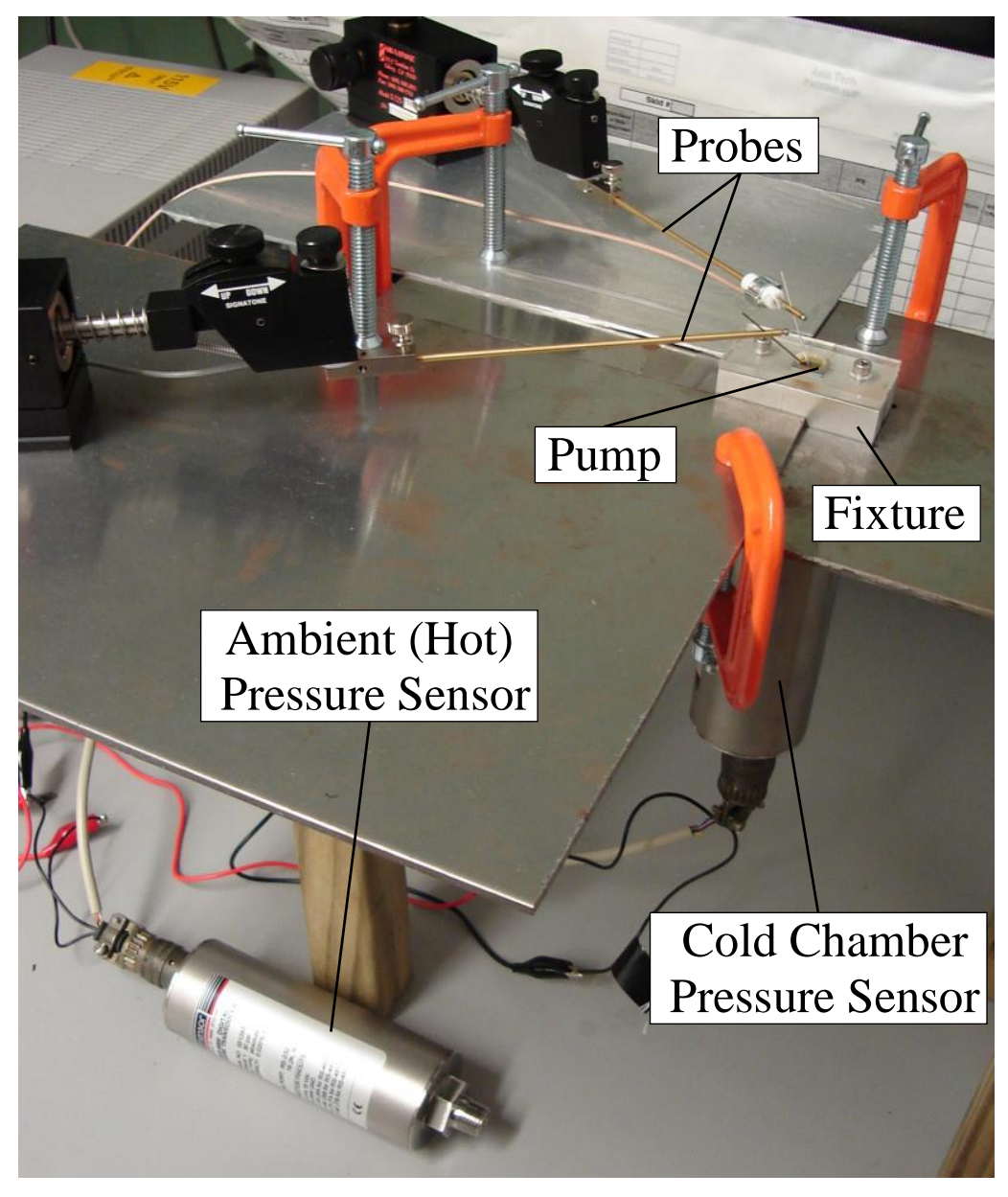

Figure 15. Experimental setup layout.

Two 30 psi Mensor ${ }^{\mathrm{TM}}$ absolute pressure sensors series 6000 , one measuring the hot and the other the cold side pressure, were connected to a computer station via RS232 and the pressures recorded using LabVIEW ${ }^{\mathrm{TM}}$. The use of this data is discussed in the next section. Figure 16 shows a detailed view of the machined fixture and how the seals are created, both between the silicon chip the pump is fabricated on and the fixture, as well as between the fixture and the pressure sensor. 


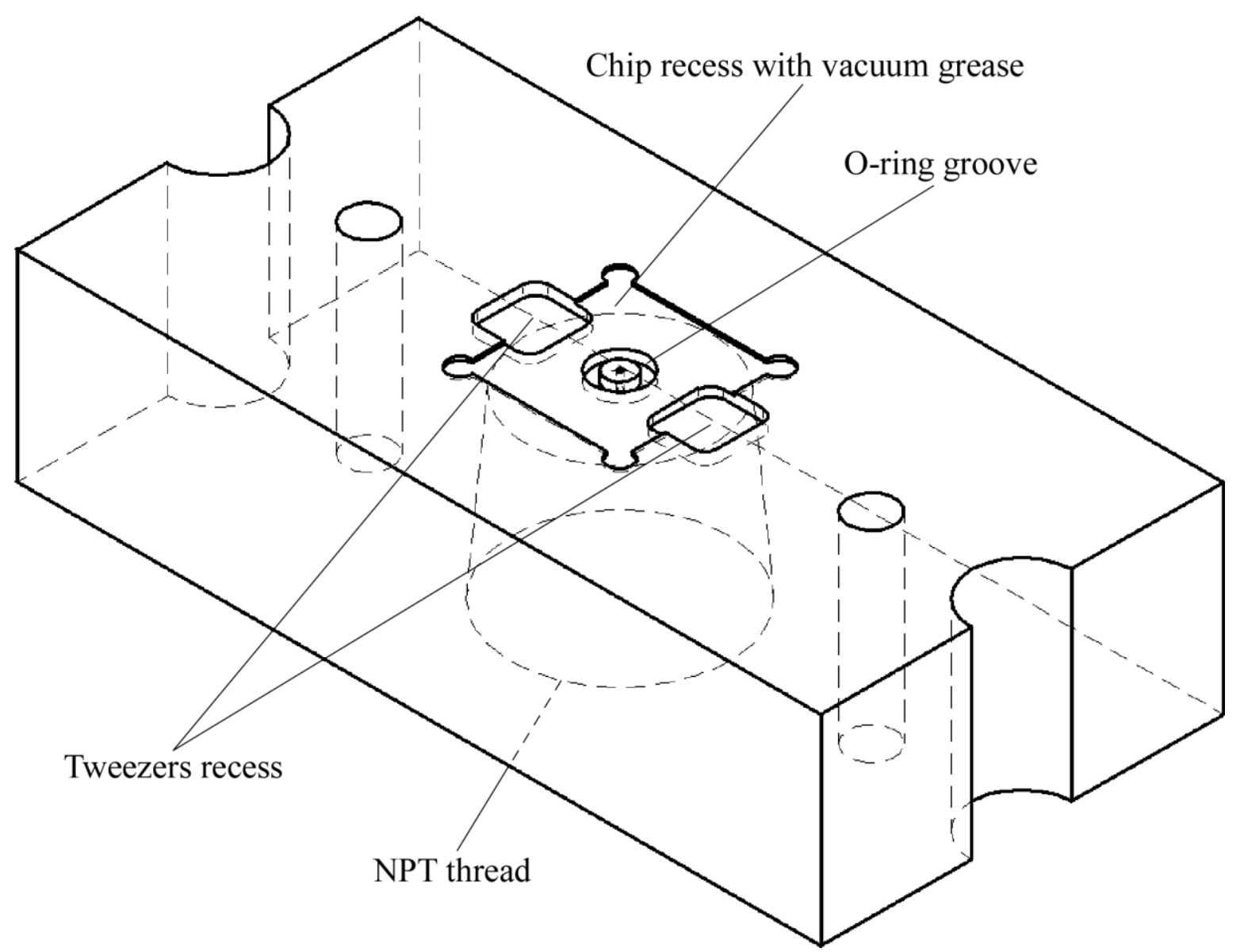

Figure 16. Detailed view of fixture and how the seals are formed.

The seal between the chip and the fixture is formed as a plastic cover (not pictured) pushes on the chip, to deform an o-ring, into a recess with added vacuum grease. The plastic cover has a large hole to give access to the heater pads (Figure 17). The sensor has a Teflon tape wrapped NPT thread sealing the cold chamber as it is screwed in the bottom of the fixture. 


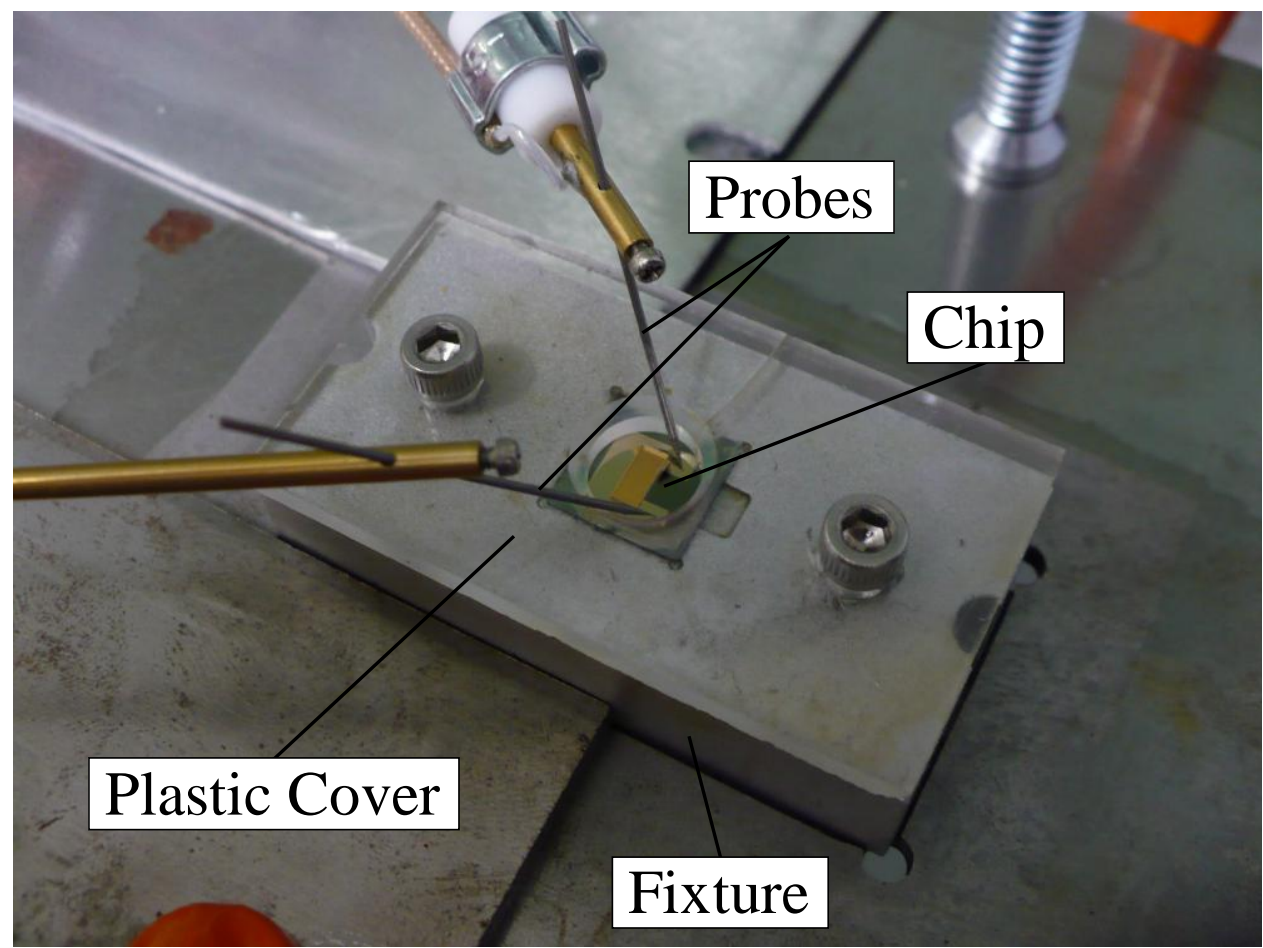

Figure 17. Detail of plastic cover which provides pressure to form the seal between the chip and the fixture.

The seals presented a challenge as even a small leak would have a great impact on the generated pressure ratio.

\subsection{Method to Calculate Pump Efficiency}

The experiment setup is capable of sensing the pressure ratio over time, while the effective temperature ratio can be obtained from this pressure ratio as the cold chamber is evacuated and the cold pressure stabilizes at equilibrium, $P_{\text {cold }}=P_{h o t} \sqrt{\frac{T_{c o l d}}{T_{h o t}}}$. At this point an approximation of the efficiency can be obtained using equation (17). A more accurate value for the efficiency can be computed if either the $T_{h o t}$ or the $T_{\text {cold }}$ is measured or calculated. Since the temperatures and pressures are known a modified version of equation (28) is used to calculate efficiency 


$$
\begin{aligned}
& \frac{\dot{Q}_{\text {hot }}}{\dot{0}}-\frac{\dot{Q_{\text {cold }}}}{\dot{m}} \\
& \eta=\frac{m_{\text {hot }} m_{\text {cold }}}{\frac{I V}{\dot{m_{\text {total }}}}}
\end{aligned}
$$

where $I V$ is the electrical power supplied to the resistance heater. Equation (31) is substituted for the mass flow rate and the equation is further simplified, which results in

$$
\eta=\frac{\bar{R}\left(T_{h o t}-T_{c o l d}\right)}{\frac{I V}{C^{\prime}}\left(\Gamma_{\text {cold }}+\Gamma_{h o t}\right)}
$$

After substituting equation (2) into equation (49) and simplification the final equation for determining the efficiency of a device is obtained

$$
\eta=\frac{\bar{R}^{\frac{3}{2}}\left(T_{\text {hot }}-T_{\text {cold }}\right)}{\frac{C^{\prime}}{\sqrt{8 \pi} l}\left(\frac{P_{\text {hot }}}{\sqrt{T_{\text {hot }}}}+\frac{P_{\text {cold }}}{\sqrt{T_{\text {cold }}}}\right)} .
$$

However, before the efficiency of the system can be calculated the conductance, in terms of $C^{\prime}$, needs to be quantified.

\subsection{Method to Calculate Channel Height}

Although here only $C_{r e c t}^{\prime}$ will be considered, a similar procedure can be applied to any $C^{\prime}$. Due to the channel being created by a grove etched in silicon and topped with a glass wafer, before the glass is bonded the width of the channel can be measured with a profilometer. Although the height of the channel can be measured, the bonding procedure may alter it. The $C^{\prime}$ can be obtained by considering the definition of conductance from equations (18) and (19), which results in 


$$
\frac{d}{d t}(P V)=\left(P_{h o t}-P_{c o l d}\right) C
$$

For a Knudsen pump with the cold chamber sealed and evacuated over time equation (51) simplifies to

$$
C=\frac{V}{P_{\text {hot }}-P_{\text {cold }}} \frac{d P}{d t}
$$

where $\frac{d P}{d t}$ is obtained by measuring the response of pressure over time due to a reduction in cold chamber volume. Once equation (39) is substituted in equation (51) the following equation for $C^{\prime}$ is formed:

$$
C^{\prime}=\frac{V}{P_{h o t}-P_{\text {cold }}} \frac{d P}{d t}\left(2 l \sqrt{\frac{2 \pi}{\bar{R} T}}\right)
$$

At this point $C_{r e c t}^{\prime}$ is used, since such a pump has been fabricated and tested, but any $C^{\prime}$ can be used. Following the substitution of equation (45) the equation for the height of the channel, $a$, is obtained

$$
\frac{32}{3 \pi^{\frac{3}{2}}} a^{2} b \ln \left(4 \frac{b}{a}+\frac{3}{4} \frac{a}{b}\right)=\frac{V}{P_{\text {hot }}-P_{\text {cold }}} \frac{d P}{d t}\left(2 l \sqrt{\frac{2 \pi}{\bar{R} T}}\right) .
$$

It should be noted that this equation can only be solved numerically for the height of the channel.

\subsection{Method to Calculate Pump Flow Rate}

Since conductance, temperatures, and pressures are known, equation (32) can be applied to obtain collisionless net mass flow in a channel

$$
\dot{m}_{n e t}=\frac{C^{\prime}}{2 l}\left(\Gamma_{\text {cold }}-\Gamma_{h o t}\right)
$$

If a transitional flow scenario is more applicable then equation (5) should be considered. 


\subsection{Overview of Fabrication Procedure}

The pump is fabricated using a three mask process followed by the bonding of the glass and silicon chip. The fabrication is largely conceived and performed by Kunal Pharas [24] and is listed here for completeness. A cross-section diagram of the pump during the fabrication procedure is shown in Figure 18.

a)

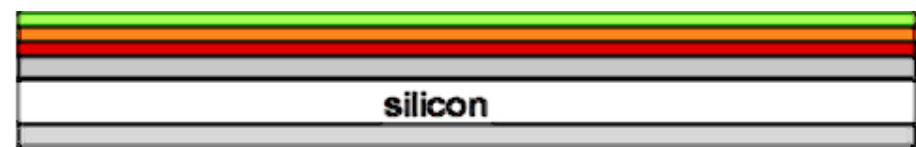

Oxidized Si wafer sputtered with $\mathrm{Cr}$, Au \& $\mathrm{Ti}$

b)

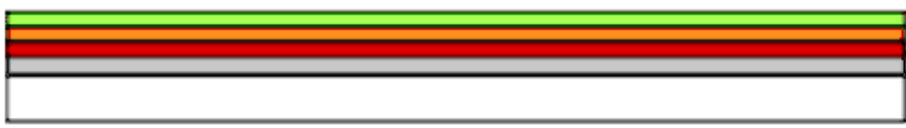

Backside oxide etched

c)

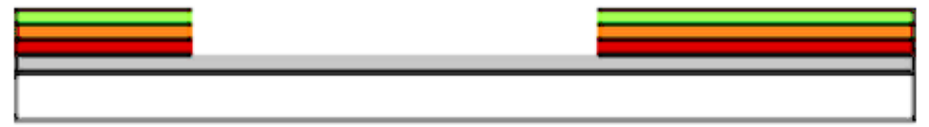

Metals etched

d)

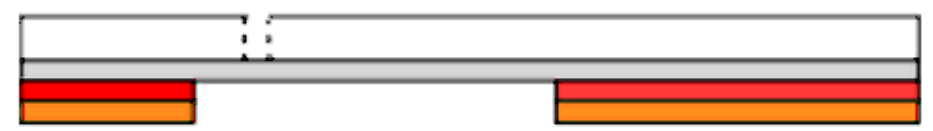

Backside etched by DRIE

e)

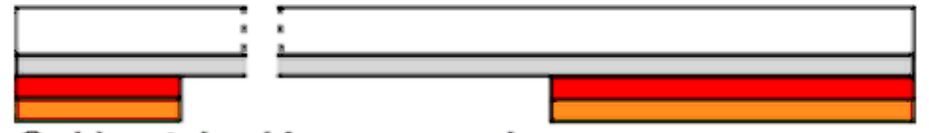

Oxide etched in oxygen plasma from backside

f)

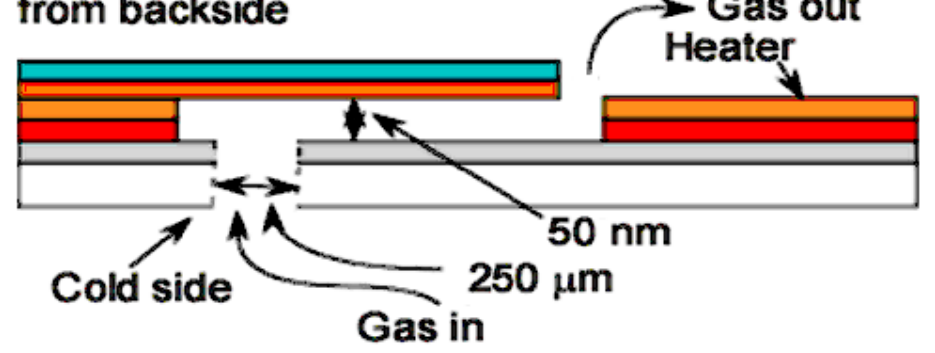

\section{Glass chip bonded on gold surface}

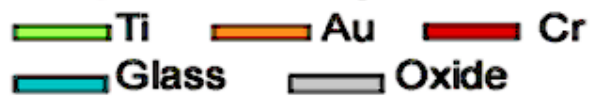

Figure 18. Fabrication Procedure, figure created by Kunal Pharas [24]. 
The fabrication procedure starts with the oxidization of a silicon wafer and the deposition of metal layers (Figure 18.a). Chromium is deposited as an adhesion layer for the gold which is to be used as the heater, while the titanium is deposited to act as an adhesion layer during the photolithography step for patterning the metal. The backside oxide is removed (Figure 18.b). Then the metal stack is etched to form a grove or recess in the surface of the wafer, which will later be partially covered by the glass chip to form the channel. An opening is then etched from the back side using DRIE that will form the cold side of the pump. The silicon wafer needs to be etched from the back first then the thermally grown oxide layer that was grown initially. Before proceeding gold is deposited on the glass chips, which are then diced. Following the dicing of the silicon wafer, individual chips are flip-chip bonded together to form the pump. The height of the channel is determined by the height of the chromium gold stack. The deposition rate is critical at this stage. The other critical step in the fabrication is the alignment of the chips prior to bonding. Figure 19 shows a top view of the fabricated pump before the glass chip is bonded to form the channel.

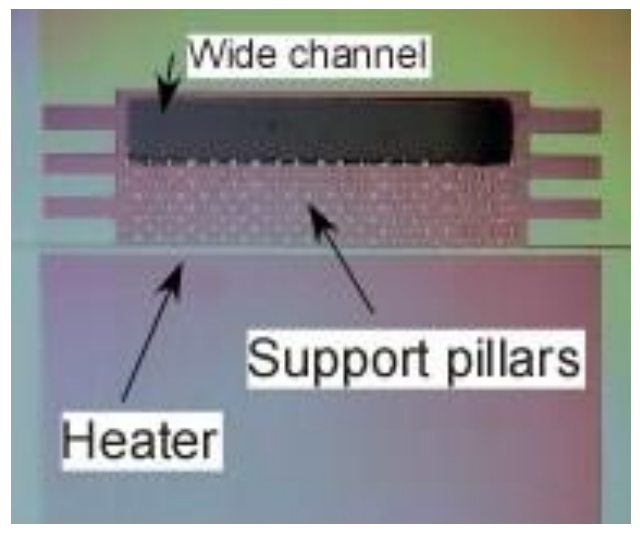

Figure 19. Top view of pump prior to bonding the glass chip to form the channel. The wide channel is the opening that has been etched from the back side. The green color is the metal stack. The heater trace is located at the entry of the hot side of the channel. The 
support pillars are located in the channel and are used to ensure that the glass chip remains flat when bonded.

\section{Experimental Pump Measurements}

The results of a pump with high thermal losses due to its geometry and a temperature difference of a few Kelvin are presented in this section. Simulation results on the temperature distribution and the design improvements are shown in chapter 5. Figure 20 shows the pressure on the hot and cold sides over time for a pump design whose characteristics are summarized in Table 5.

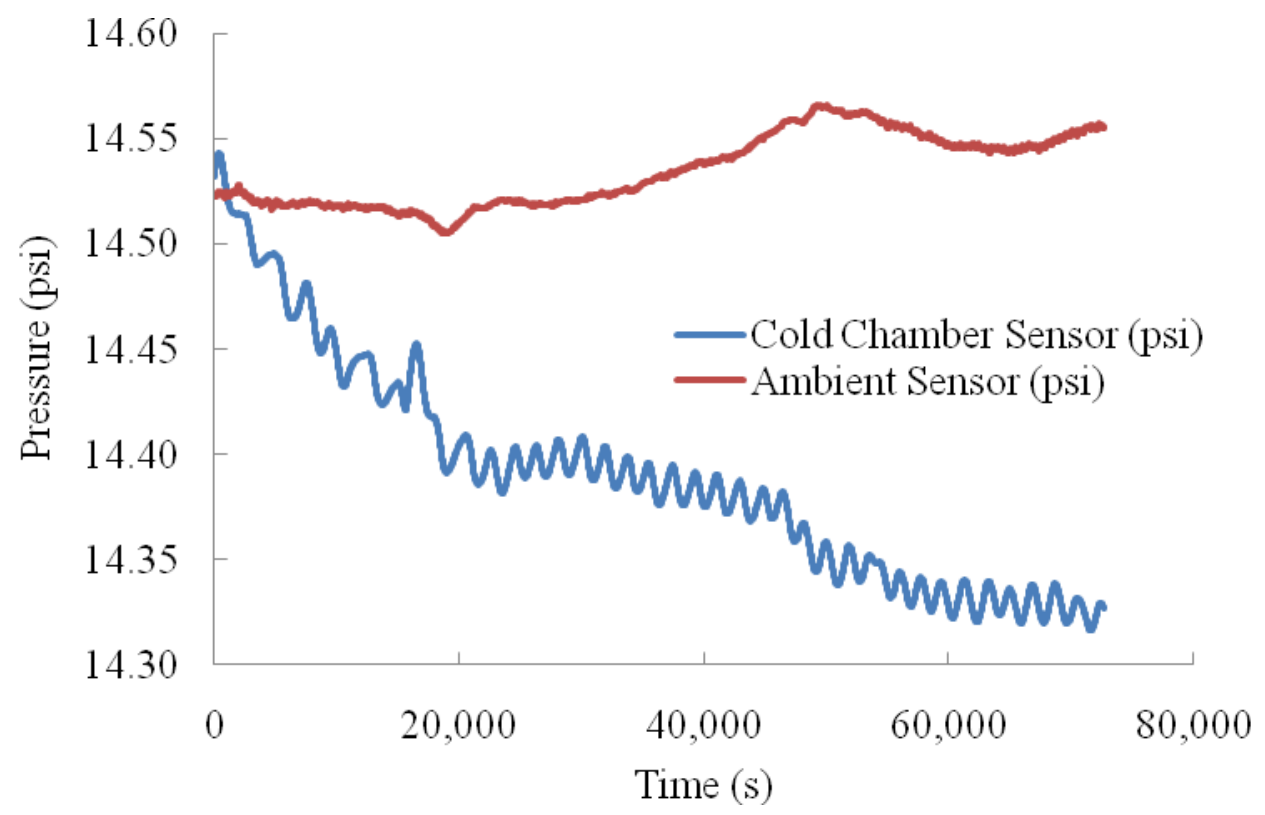

Figure 20. Pressure on the hot side of the pump (ambient) and the cold side.

\begin{tabular}{|c|c|}
\hline Substrate & Silicon \\
\hline \hline Top cover & Pyrex \\
\hline Substrate thickness & $500 \mu \mathrm{m}$ \\
\hline Channel width & $1355 \mu \mathrm{m}$ \\
\hline Channel length & $340 \mu \mathrm{m}$ \\
\hline $\begin{array}{c}\text { Heater to channel } \\
\text { opening distance }\end{array}$ & $50 \mu \mathrm{m}$ \\
\hline
\end{tabular}

Table 5. Characteristics of tested pump. 
The ambient pressure is on the hot side and does not change greatly, while the cold pressure is the pressure inside the cavity that is evacuated. The maximum pressure difference that is developed is $0.227 \mathrm{psi}$, while the pressure ratio that is developed is 1.0158 and the temperature ratio calculated from this is 1.0320 . Simulations show that the hot temperature is approximately $421.5 \mathrm{~K}$. Due to the heat largely going towards increasing the temperature of the fixture and the very low temperature ratio that is generated this is a very inefficient design, whose initial efficiency is only about $0.001436 \%$. The efficiency will decrease as the chamber is evacuated. It is anticipated that several orders of magnitude improvement may be obtainable by increasing the temperature ratio and/or reducing the thermal losses through an improved design. Thermal simulations for an improved design using a suspended heater with greater thermal isolation will be presented in the next chapter. 


\section{CHAPTER V}

\section{SIMULATIONS}

\subsection{Simulation Overview}

A better understanding of Knudsen pump design for high efficiency operation can be gained by applying the equations obtained in the previous chapters and simulating the temperature distribution of the designs. In chapter 4 it was found that heating the fixture drastically reduces the efficiency of the pump.

\subsection{Simulation of Current Design}

The model geometry of the ANSYSTM simulation for the design detailed in section 4.4 is shown in Figure 21, while Figure 22 shows a detail of the heater.

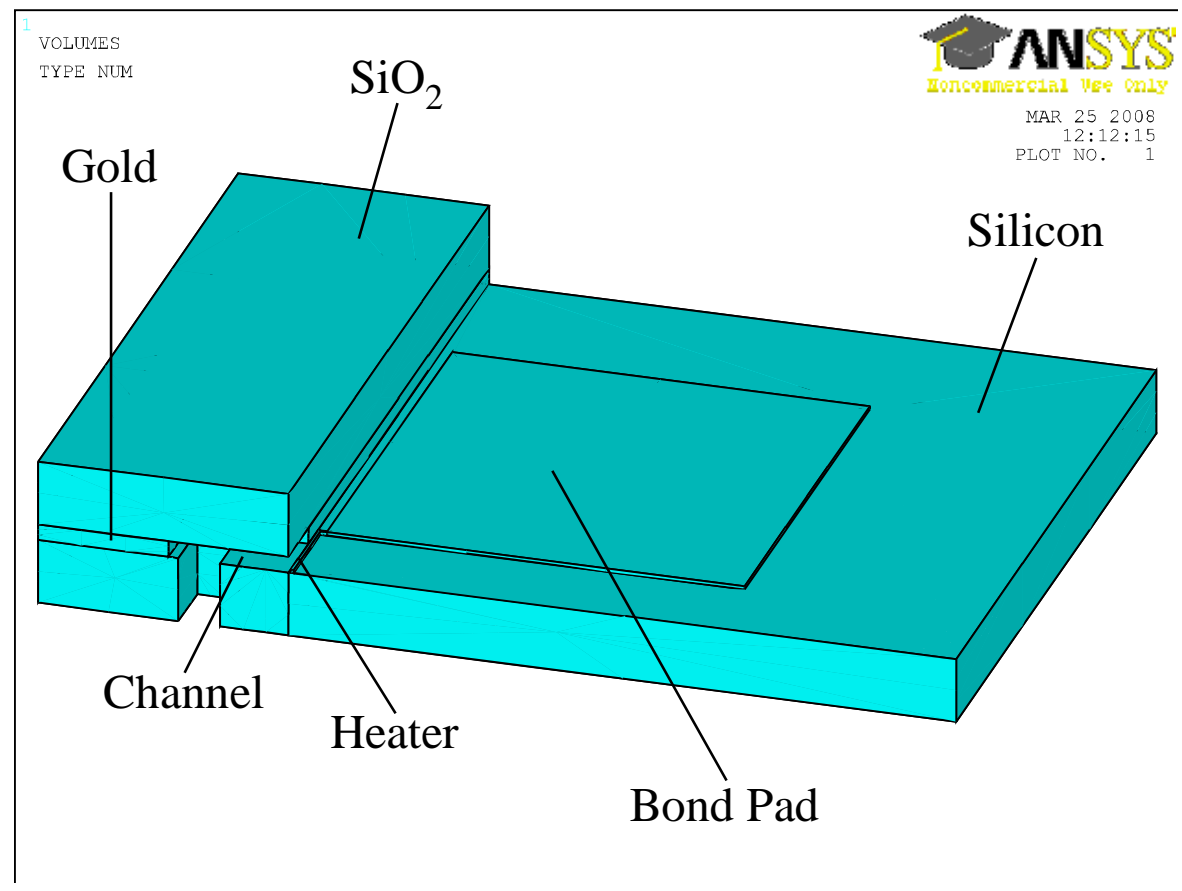

Figure 21. Cross-section of the chip shows the channel from pump design in section 4.4. 


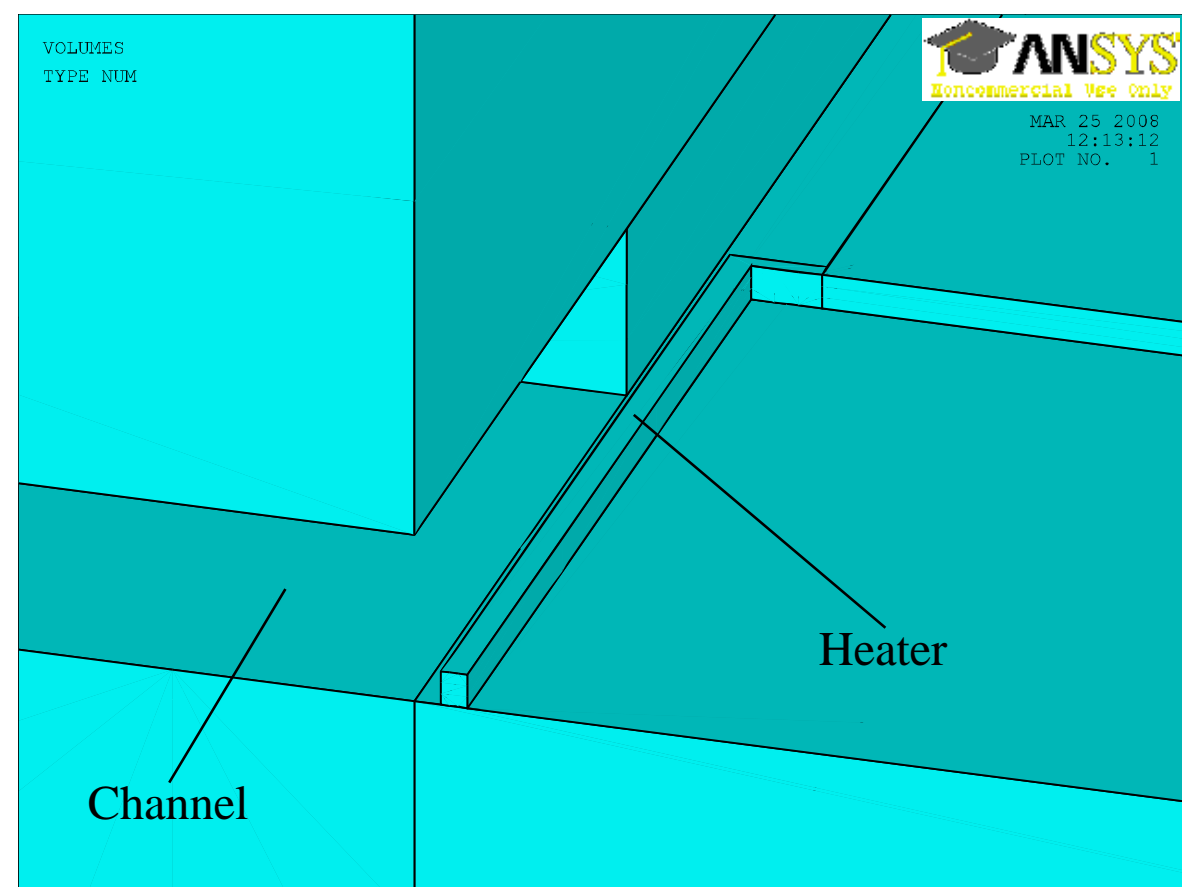

Figure 22. Detail of the heater trace and cross-section of the channel from the pump design in section 4.4.

Figures 21 and 22 each show the narrow channel of the Knudsen pump in half symmetry. The material selection in this design should be noted, as the improved design varies in the material selection as well as the heater design. The cap that forms the channel is a glass chip, while the interconnecting layer and heater are gold. The boundary conditions that are imposed on this thermal simulation and the one of the improved design are as follows: the bottom surface is assumed to be at room temperature, convection is taking place from all of the top surfaces, and the heater reaches 500K. Figure 23 and 24 show the temperature distribution generated under these conditions. Detailed characteristics of the model can be found in the input files attached in the appendix. The height of the heater trace and bond pad was reduced to better view the model, the error introduced by this is well within one percent. 


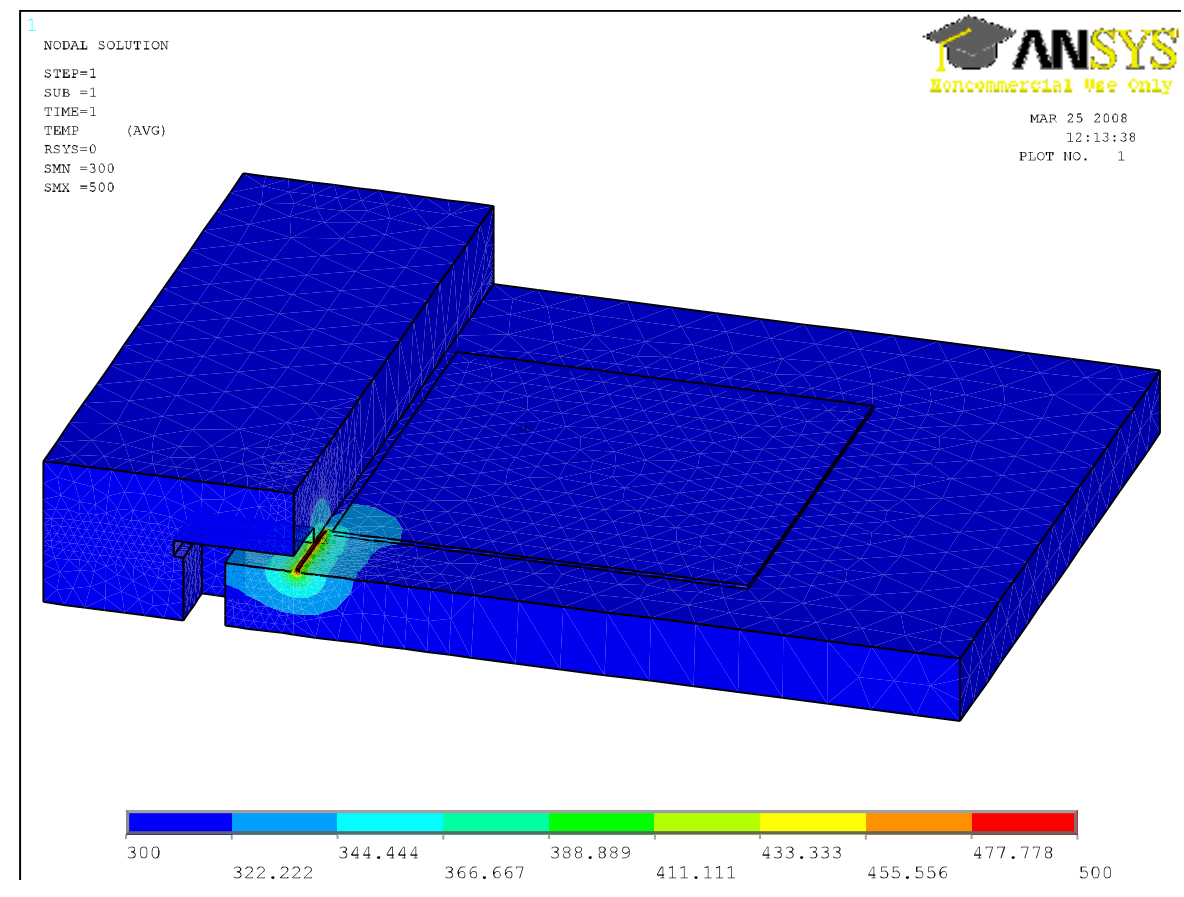

Figure 23. Temperature distribution along channel generated by a gold heater trace on the silicon chip.

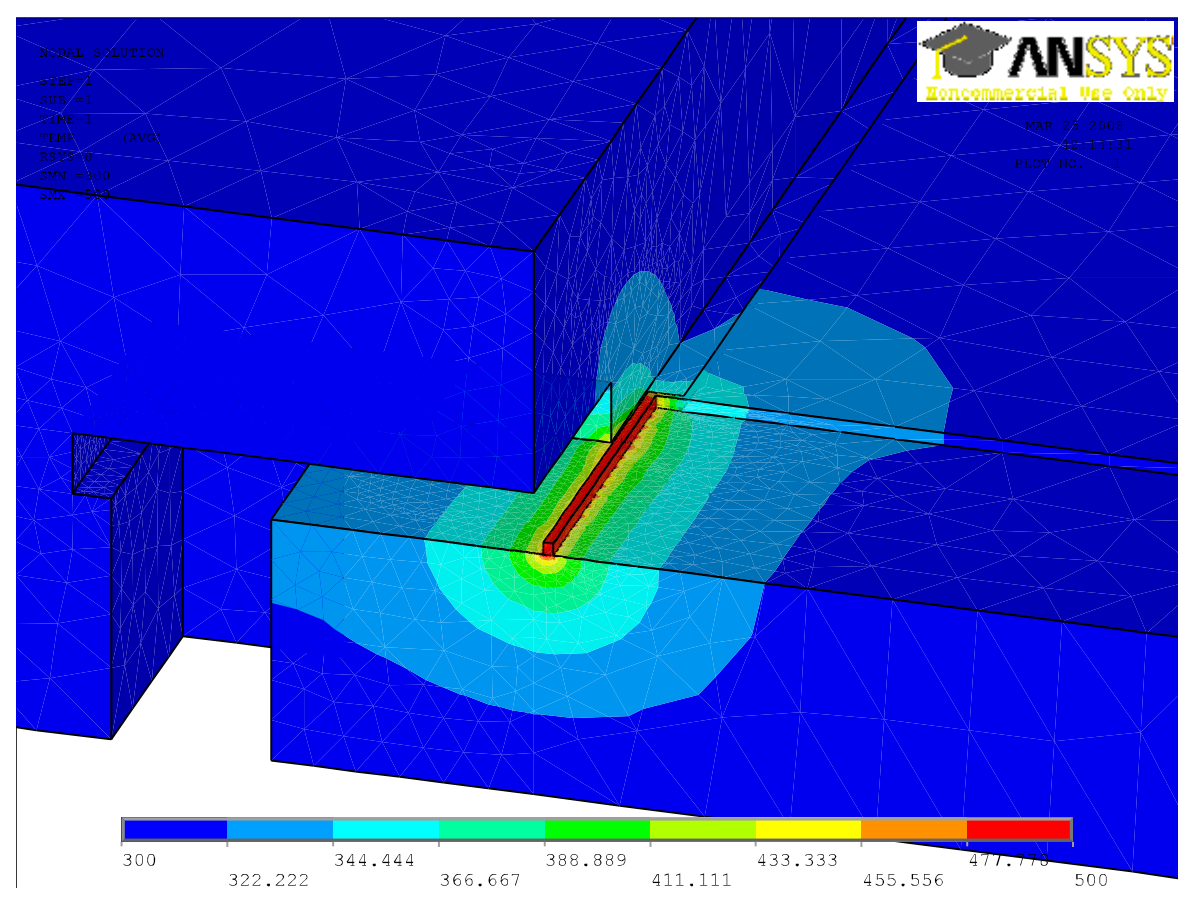

Figure 24. Detailed view of temperature distribution along channel. 
In practice the temperature ratios that have been inferred from the experimentally obtained equilibrium pressure ratio have been significantly lower, indicating that the assumption that the bottom surface is at room temperature may not be very representative of the physically accurate problem. The temperature distribution along the channel is given in Figure 25.

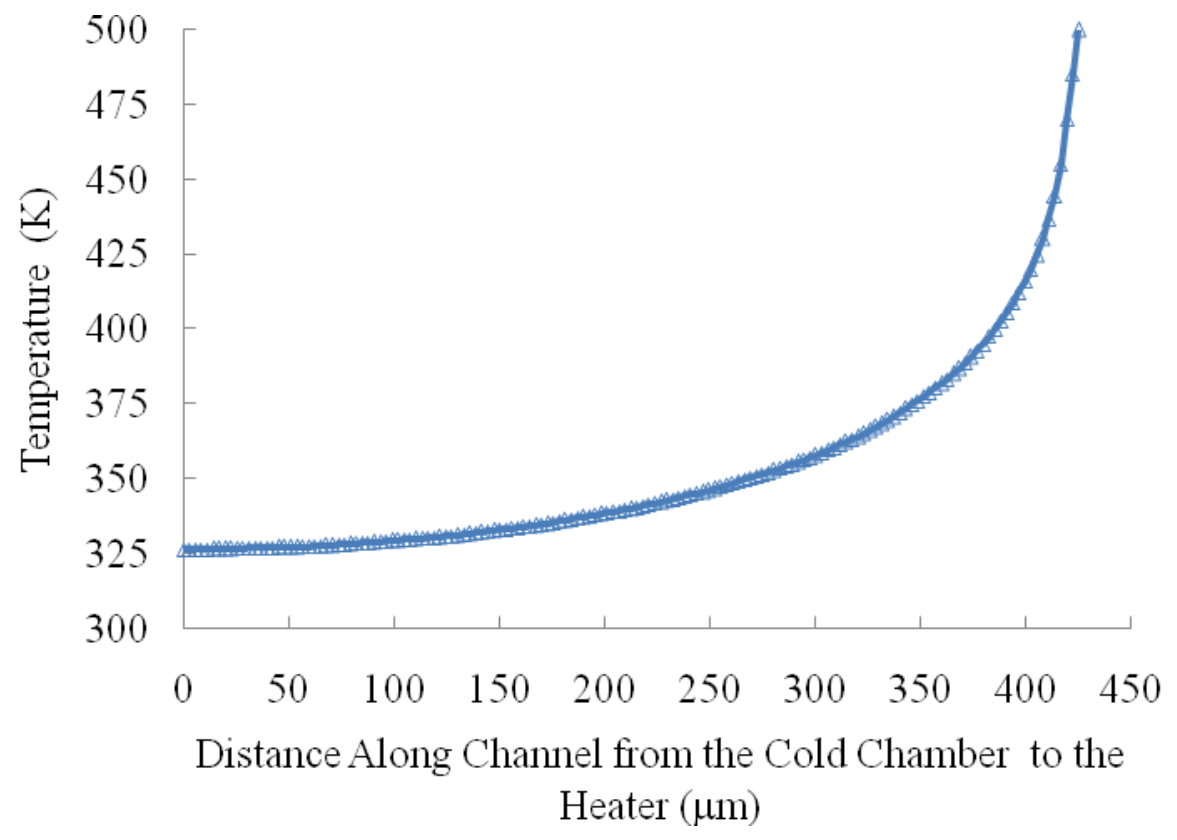

Figure 25. Temperature distribution along the channel for the design detailed in section 4.4 One of the problems associated with this design is that large portions of the fixture are heated, decreasing the total efficiency of the design. The second problem with this design is that the temperature on the cold side of the pump does not return to room temperature, reducing the temperature ratio and with that the total efficiency. The temperature on the cold side could be reduced to room temperature if better thermal management was implemented in the design.

\subsection{Simulation of Design with suspended Heater}

The improved design is shown in Figure 26. A detailed view of the heater is shown in Figure 27. Figure 28 and 29 show the temperature distribution of improved design. 


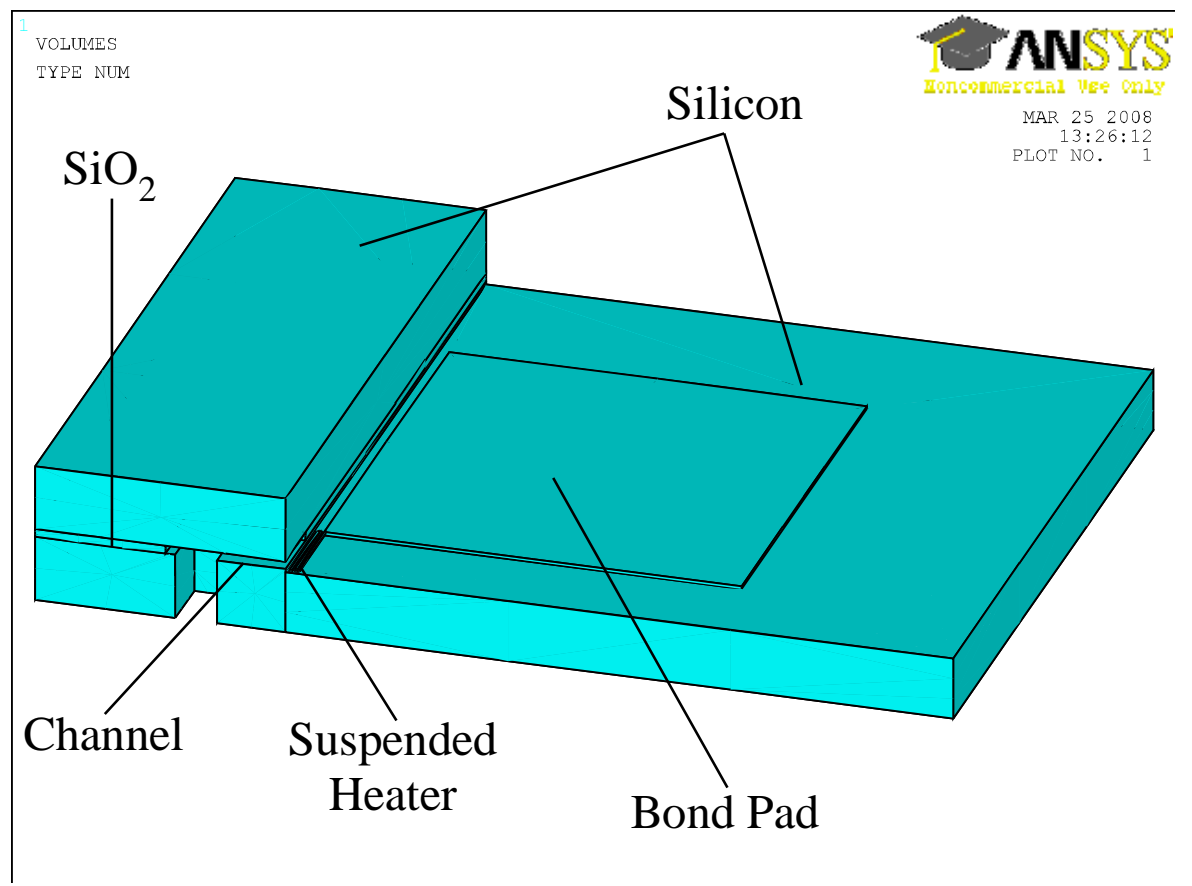

Figure 26. Improved design layout and material selection.

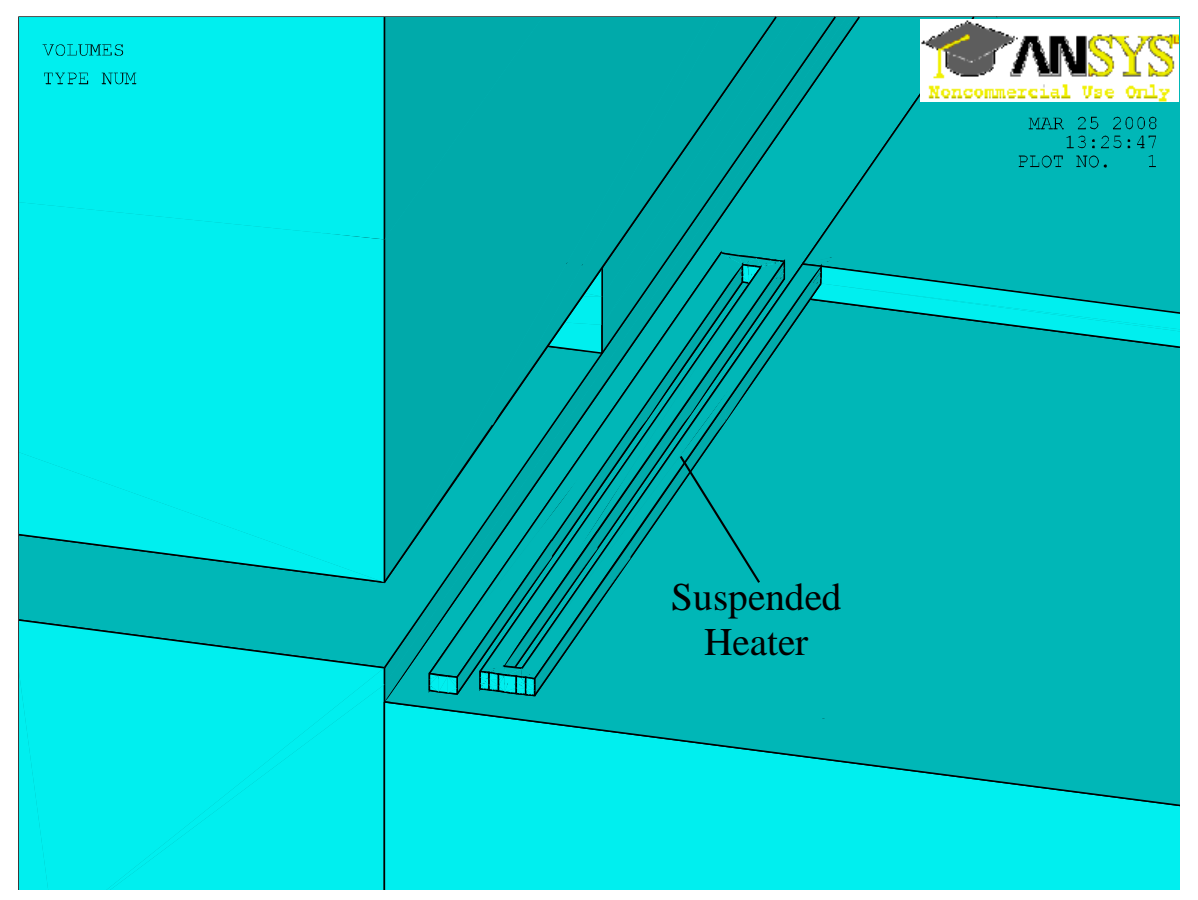

Figure 27. Detail of improved heater design, which is suspended from the bond pad. 


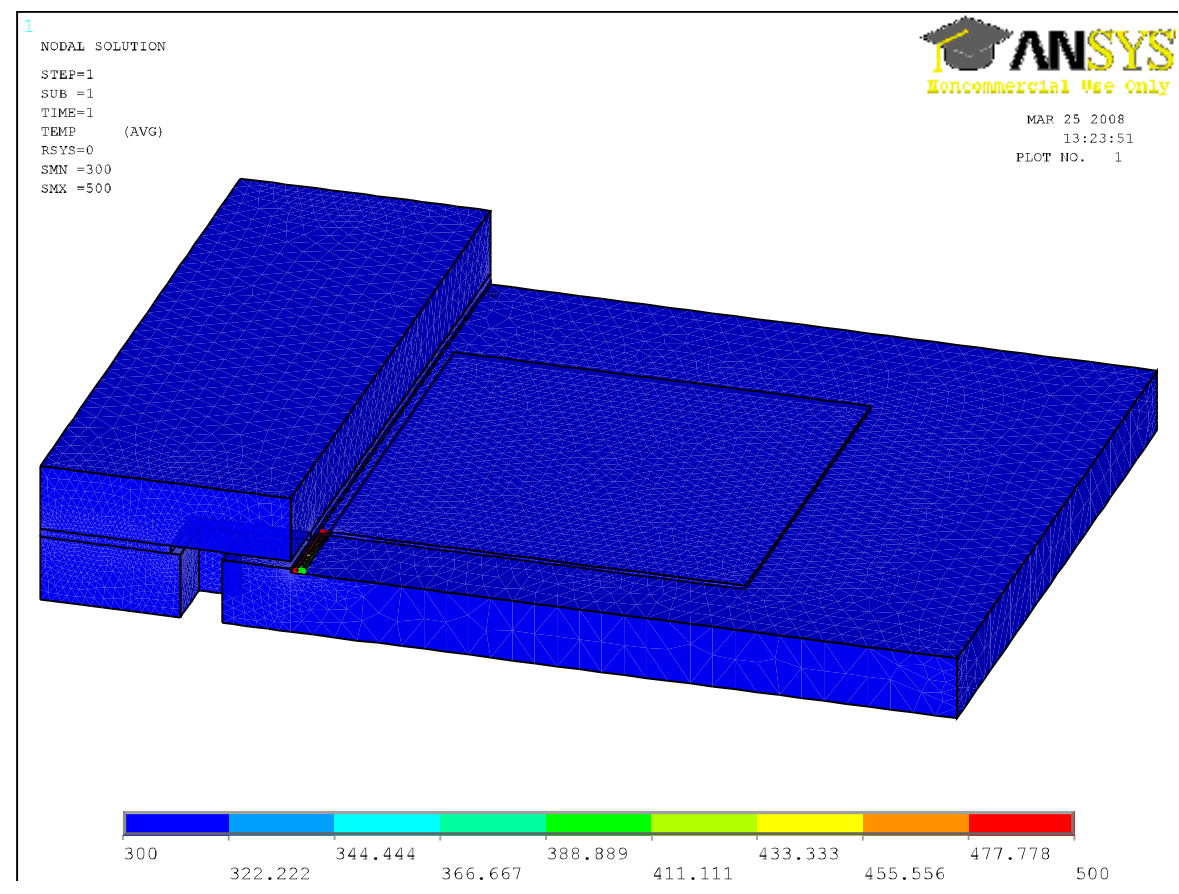

Figure 28. Temperature distribution in the fixture using suspended heater design.

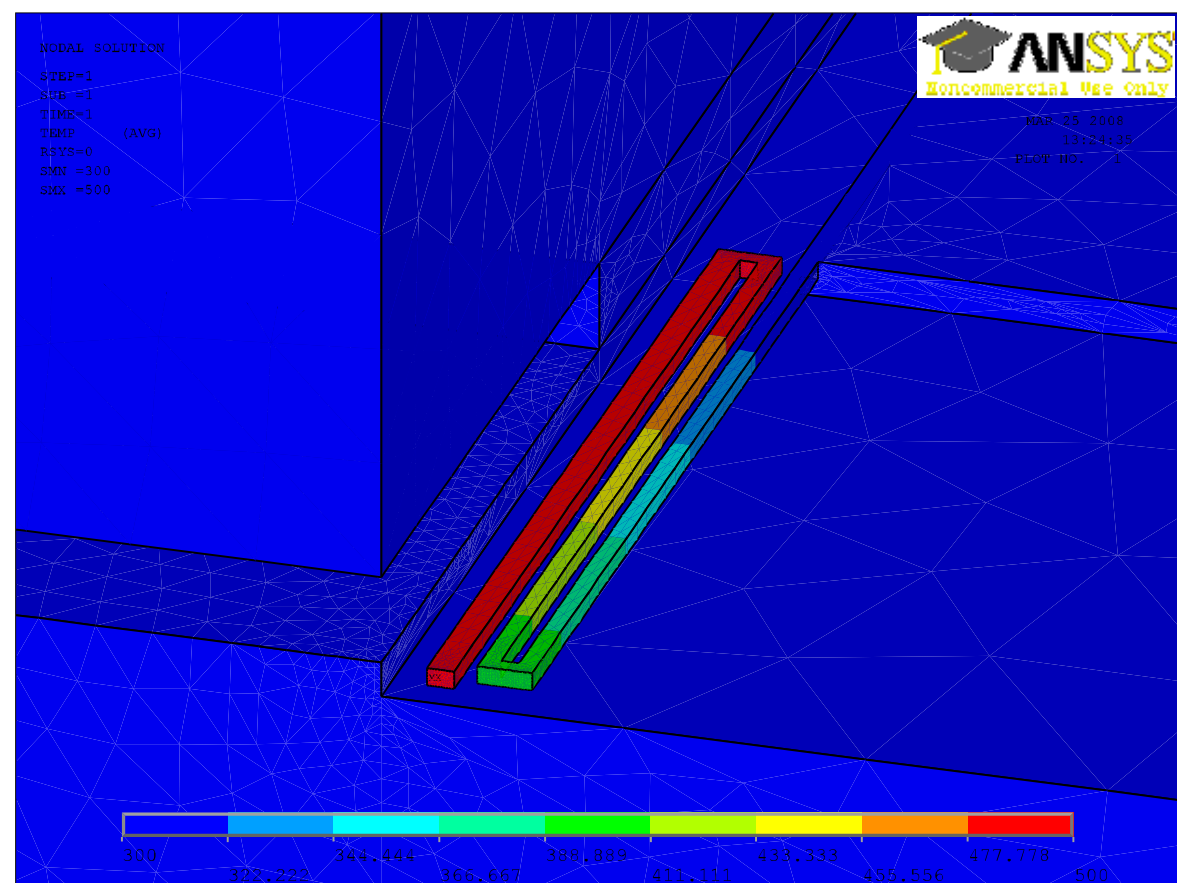

Figure 29. Temperature distribution in the suspended heater.

Although the improved design looks similar to Figure 21, the top chip is fabricated out of silicon instead of glass and the layer between chips is silicon oxide instead of a gold 
chromium stack. The heater is no longer in contact with the silicon surface and is instead suspended from the bond pad. This reduces the energy consumption as the fixture is not heated. The heat only goes towards the heating of the gas and the heater trace. The new design is currently being fabricated. 


\section{CHAPTER VI}

\section{CONCLUSIONS AND FUTURE RESEARCH DIRECTIONS}

\subsection{Conclusions}

This thesis presents equations for the efficiency of a Knudsen pump, both, with losses and without. These equations further the understanding of the applicable uses of the pump and guide designs to avoid energy losses. The equation for collisionless flow in the molecular regime through an aperture without energy losses was found in chapter 2 to be:

$$
\eta_{\text {ideal }}=\frac{R}{C_{p}}\left(\frac{\sqrt{\frac{T_{h o t}}{T_{\text {cold }}}}-\frac{P_{\text {hot }}}{P_{\text {cold }}}}{\frac{P_{\text {hot }}}{P_{\text {cold }}}+\sqrt{\frac{T_{h o t}}{T_{\text {cold }}}}}\right) .
$$

This equation is useful for understanding how the efficiency of the pump is affected by different temperature and pressure regimes. The efficiency of the pump is limited by the ratio of the universal gas constant to the specific heat of the gas, which varies for different gases and may allow for gas separation using waste heat. This equation shows that, to maximize efficiency, the pressure ratio should be minimized and the temperature ratio should be maximized. The equation also never exceeds one and has an efficiency of zero at equilibrium. It should be noted that this behavior is not imposed upon the equation, but results from it.

In chapter 3 , the thermal losses along the channel are accounted for and a more accurate equation for the pump efficiency is found to be 


$$
\eta=\frac{R}{C_{p}}\left(\frac{\sqrt{\frac{T_{h o t}}{T_{\text {cold }}}}-\frac{P_{\text {hot }}}{P_{\text {cold }}}}{\frac{P_{\text {hot }}}{P_{\text {cold }}}+\sqrt{\frac{T_{\text {hot }}}{T_{\text {cold }}}}+\left(\sqrt{2 \pi \bar{R} T_{\text {hot }}} \frac{2}{C^{\prime}} \frac{M}{C_{p}} \frac{A_{\text {cond }} k}{P_{\text {cold }}}\right)}\right) .
$$

This equation provides insight into the detrimental effect the thermal losses can have on the overall efficiency, particularly if heat conduction along the channel is used to generate the temperature ratio. The impact of large thermal losses is quantified in the illustrative example in chapter 4, while chapter 5 contains ANSYSTM simulations showing an improved design that avoids heating the fixture and which is predicted to provide a substantial improvement in efficiency.

Methods for obtaining the efficiency, flow rate, and the height of the channel are described in chapter 4. Obtaining the conductance in terms of $C^{\prime}$ for the specific crosssection is key for determining these values. The described methods and equations require that the generated pressure ratio at equilibrium and at least one of the temperatures are known.

\subsection{Potential Application to be investigated}

Some of the applications of the Knudsen pump have been mentioned in the above section. Two novel applications already mentioned include forced convection cooling for applications with photovoltaics for instance and the integration of the Knudsen pumps with chemical preconcentrators. Since the Knudsen pump performs well in environments where a large temperature ratio can be easily generated, applications in environments such as high orbit or perhaps even space should be investigated. An exciting possibility is a space engine, which would have applications for weather balloons and for preventing the decay of low satellite orbits. Such an engine would benefit from a large temperature ratio that can be 
generated using solar irradiation and from the large mean free path due to low pressures. The increased mean free path would allow for larger Knudsen pumps to be constructed.

\subsection{Future Work}

Future work should focus on expanding the efficiency model to include gas flows that are in the transition regime and to include surface effects. An improved thermal model needs to be developed that incorporates more accurate boundary conditions. The new pump design with the suspended heater also needs to be investigated. The thermal losses in the efficiency equation for varying heating methods needs to be quantified, as newer designs of MEMS fabricated Knudsen pumps will undoubtedly try to use different geometries to reduce the thermal conduction losses. Finally, potential applications also need to be further investigated. 


\section{REFERENCES}

1. Chollet, F. and H.B. Liu. A (not so) Short Introduction to Micro Electromechanical Systems. 2007 July: http://memscyclopedia.org/introMEMS.html.

2. Eatony, W.P. and J.H. Smith, Micromachined pressure sensors:review and recent developments. Smart Mater, 1997. Struct.(6): p. 503-539.

3. MEMSIC. MEMSIC - Solutions that make sense. 2006: www.memsic.com.

4. Wilson, D.M., et al., Chemical Sensors for Portable, Handheld Field Instruments. IEEE Sensors Journal, 2001. 1(4): p. 256-274.

5. Tanner, D.M., et al., On-Chip Monitoring of MEMS Gearmotion, in 41st Annual International Reliability. 2003: Dallas, Texas.

6. Jaeger, R.C., Introduction to Microelectronic Fabrication. Second ed. Modular Series on Solid State Devices, ed. G.W. Neudeck and R.F. Pierret. Vol. 5. 1998, Upper Saddle River, New Jersey: Prentice Hall. 316.

7. Texas Instruments Inc., D. DLP Technology - HDTV, DLP Projectors, Cinema and Home Theater. 2008: www.dlp.com.

8. Ghandhi, S.K., VLSI Fabrication Principles: Silicon and Gallium Arsenide. 1994, New York: John Wiley \& Sons, Inc.

9. Knudsen, M., Kinetic Theory of Gases: Some Modern Aspects. Third ed. 1950, London: Methuen \& Co. Ltd. 64.

10. Kennard, E.H., Kinetic Theory of Gases: With an Introduction to Statistical Mechanics. 1938, New York: McGraw-Hill Book Company, Inc.

11. Sone, Y., Kinetic Theory and Fluid Dynamics. 2002, Boston: Brickhaeuser. 353.

12. Livesey, R.G., Flow of Gases through Tubes and Orifices, in Foundations of Vacuum Science and Tehnology, J.M. Lafferty, Editor. 1998, John Wiley \& Sons, Inc.: Canada. p. 81-140.

13. Muntz, E.P. and S.E. Vargo, Micro Scale Vacuum Pumps, in The MEMS Handbook, M. Gad-el-Hak, Editor. 2002, CRC Press.

14. Muntz, E.P., et al., Performance Analysis and optimization for a Knudsen Compressor in Transitional Flow. The Journal of Vacuum Science and Technology, 2002. A(1).

15. Han, Y.L., et al. Knudsen Compressor Performance at Low Pressures. 2005: AIP.

16. Sazhin, O., et al., Numerical analysis of gas-surface scattering effect on thermal transpiration in the free molecular regime. Vacuum, 2007. 82(1).

17. McNamara, S. and Y.B. Gianchandani, On-Chip Vacuum Generated by a Micromachined Knudsen Pump. Journal of Microelecromechanical Systems, 2005. 14(4): p. 6.

18. Gupta, N.K. and Y.B. Gianchandani, A Knudsen Pump using Nanoporous Zeolite for Atmospheric Pressure Operation, in MEMS 2008. 2008: Tucson, AZ, USA.

19. Hobson, J.P. and D.B. Salzman, Review of pumping by thermal molecular pressure. Journal of Vacuum Science and Technology A, 2000. 18(4): p. 1758-1765. 
20. Haefer, R.A., Cryogenic vacuum techniques. Journal of Physics E: Scientific Instruments, 1981(3): p. 273.

21. Knudsen, M., Ann. Phys. (Leipzig), 1909. 28(4): p. 999-1016.

22. Dushman, S., Chapter 2, in Scientific Foundations of Vacuum Technique. 1949, Wiley: New York.

23. Smoluchowski, M., Ann. Phys. (Leipzig), 1910. 33(4): p. 1559.

24. Pharas, K., et al., A MEMS Gas Pump with No Moving Parts, in Thirteenth Annual Kentucky EPSCoR Conference. 2007: Lexington, Kentucky. 


\section{APPENDIX A}

\section{ANSYS ${ }^{\text {TM }}$ input file for the design shown in section 4.4}

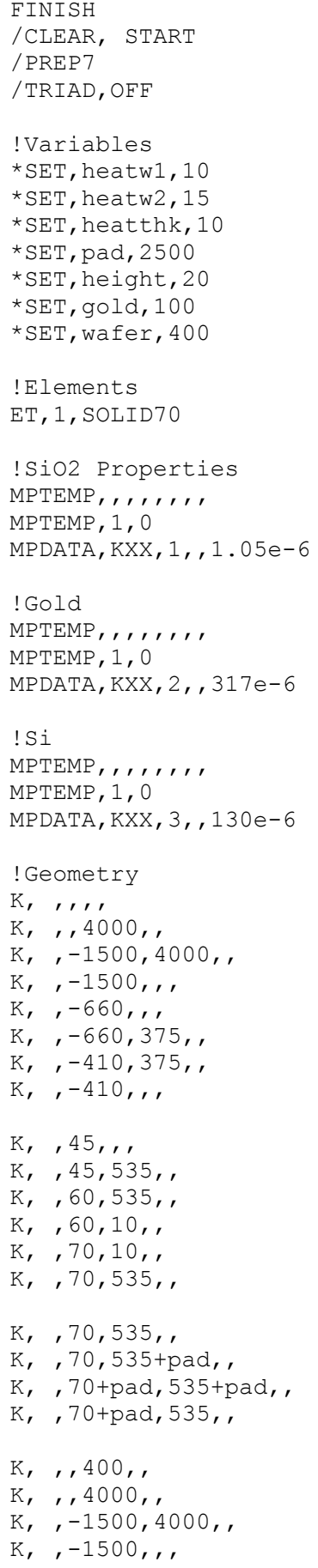


$\mathrm{K}, \quad,-720,,$,

$\mathrm{K}, \quad,-720,400$, ,

LSTR, $\quad 9, \quad 10$

LSTR, 10, 11

LSTR, 11, 12

LSTR, 12, 13

LSTR, 13, 14

FLST, 2, 4, 3

FITEM, 2, 15

FITEM, 2, 16

FITEM, 2, 17

FITEM, 2, 18

A, P 51X

FLST $, 2,8,3$

FITEM, 2, 1

FITEM, 2, 2

FITEM, 2, 3

FITEM, 2, 4

FITEM, 2, 5

FITEM, 2, 6

FITEM, 2, 7

FITEM, 2, 8

A, P $51 X$

FLST, 2, 6, 3

FITEM, 2, 19

FITEM, 2, 20

FITEM, 2, 21

FITEM, 2, 22

FITEM, 2, 23

FITEM, 2, 24

A, P $51 X$

$\mathrm{K}, \quad, 0,0,0$,

$K, \quad, 0,4000,0$,

$\mathrm{K}, 4000,4000,0$,

$\mathrm{K}, 4000,0$,

FLST , 2, 4, 3

FITEM, 2, 25

FITEM, 2, 26

FITEM, 2, 27

FITEM, 2, 28

A, P $51 X$

$\mathrm{K}$, , , , gold,

$\mathrm{K}$, , ,4000, gold,

K, , $-1500,4000$, gold,

$\mathrm{K}$, , -1500, ,gold,

FLST , 2, 4, 3

FITEM, 2, 29

FITEM, 2, 30

FITEM, 2, 31

FITEM, 2, 32

A, P $51 X$

/VIEW $, 1, .3,-1, .5$

/VUP, 1, Z

/REPLOT

aplo

FLST , 2, 1, 5, ORDE, 1

FITEM, 2, 1

VEXT, P51X, , , 0, 0, height, , , ,

FLST , 2, 1, 5, ORDE, 1

FITEM, 2, 4

VEXT, P51X, , ,0,0,-wafer, , , 


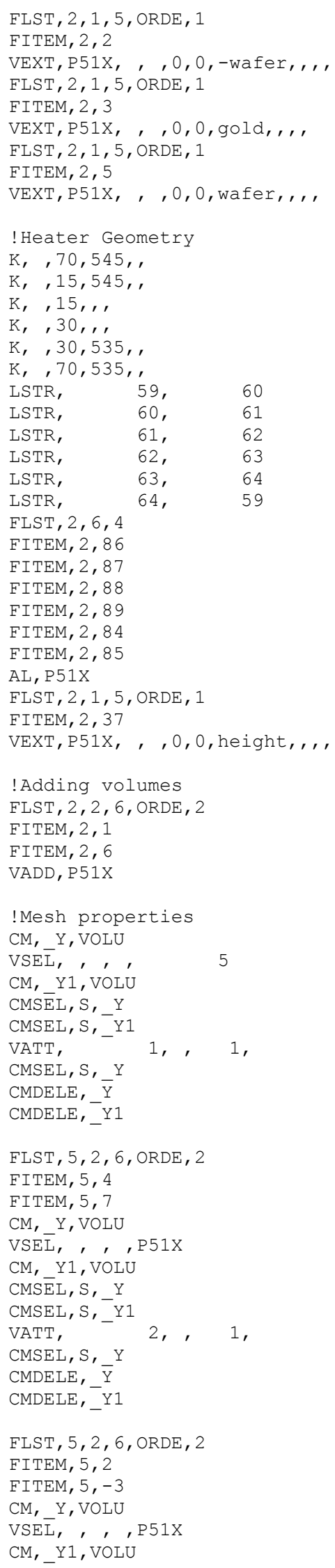




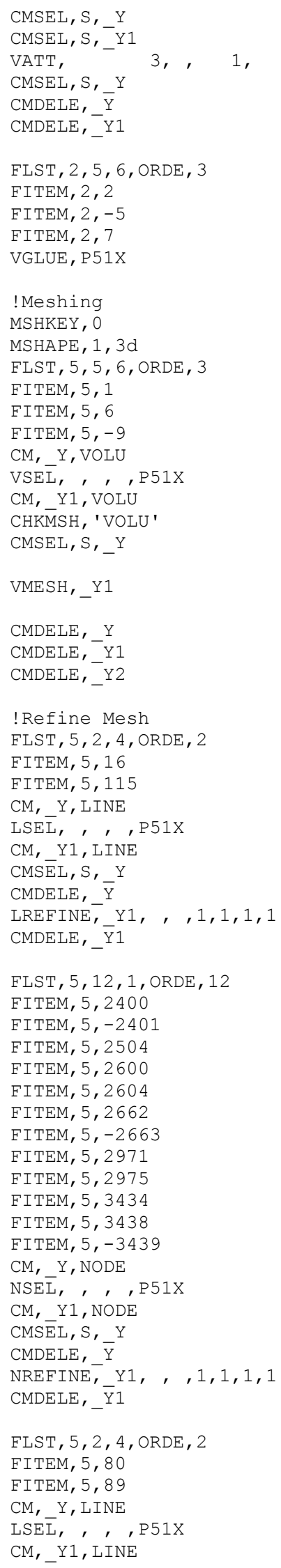




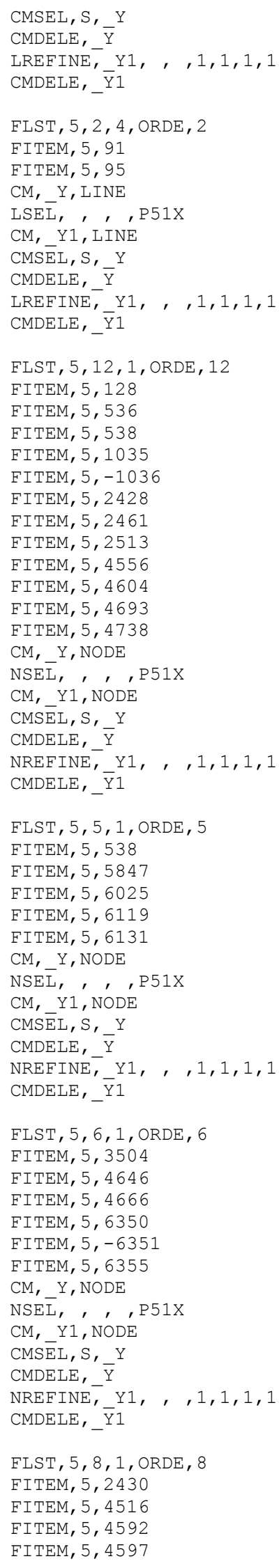




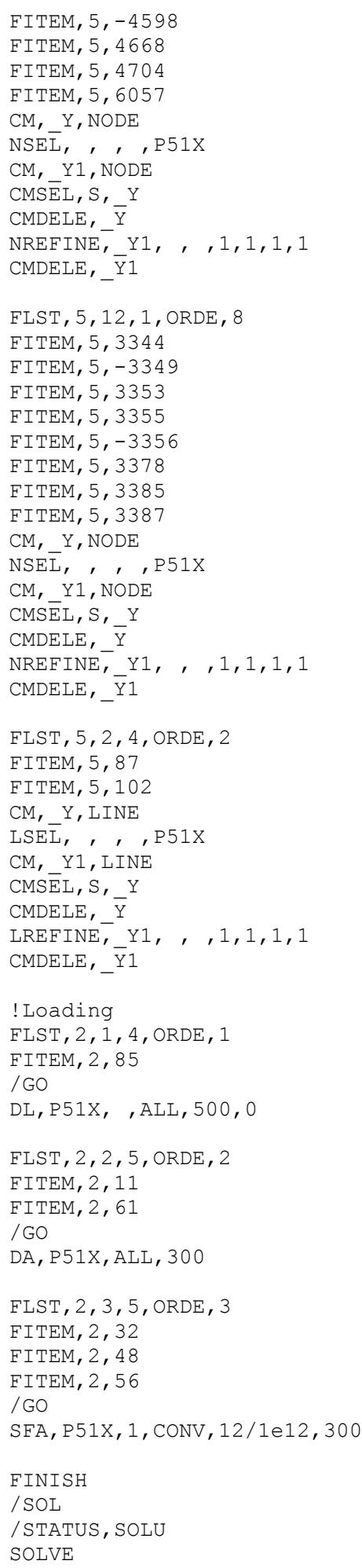




\section{APPENDIX B}

\section{ANSYSTM input file for the improved design chapter 5.}

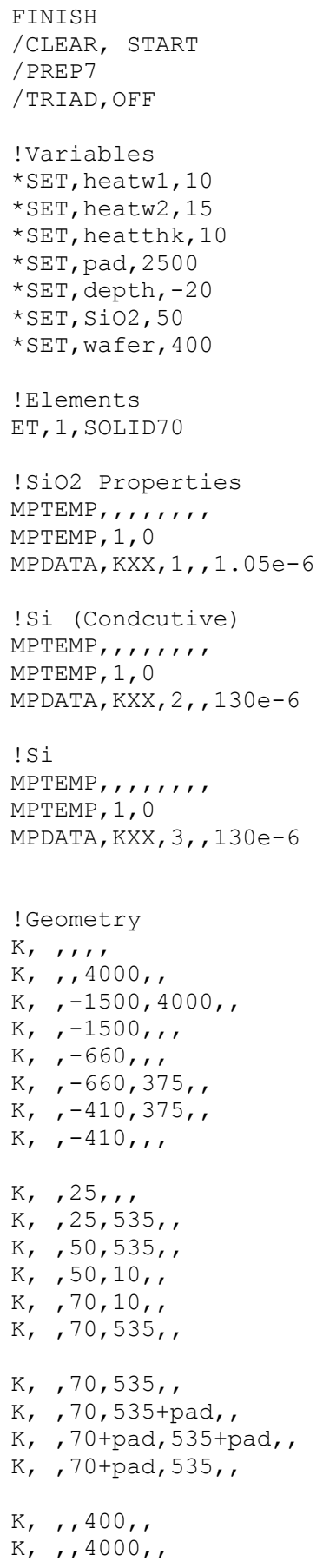




\begin{tabular}{|c|c|c|}
\hline \multicolumn{3}{|c|}{ 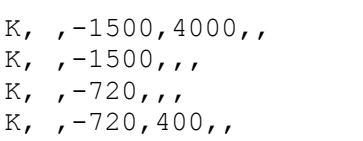 } \\
\hline LSTR, & 9, & 10 \\
\hline LSTR, & 10, & 11 \\
\hline LSTR, & 11, & 12 \\
\hline LSTR, & 12, & 13 \\
\hline LSTR, & 13, & 14 \\
\hline
\end{tabular}

FLST $, 2,4,3$

FITEM, 2, 15

FITEM, 2, 16

FITEM, 2, 17

FITEM, 2, 18

A, P $51 X$

FLST, 2, 8, 3

FITEM, 2, 1

FITEM, 2, 2

FITEM, 2, 3

FITEM, 2, 4

FITEM, 2, 5

FITEM, 2, 6

FITEM, 2, 7

FITEM, 2, 8

A, P $51 X$

FLST , 2, 6, 3

FITEM, 2, 19

FITEM, 2, 20

FITEM, 2, 21

FITEM, 2, 22

FITEM, 2, 23

FITEM, 2, 24

A, P $51 X$

$K, \quad, 0,0$, depth,

$K, \quad, 0,4000$, depth,

K, ,4000,4000, depth,

K, ,4000, depth,

FLST, 2, 4, 3

FITEM, 2, 25

FITEM, 2, 26

FITEM, 2, 27

FITEM, 2, 28

A, P $51 X$

$\mathrm{K}$, , , , SiO2,

$\mathrm{K}$, , ,4000, SiO2,

K, , $-1500,4000$, SiO2,

K, ,-1500, ,Sio2,

FLST $, 2,4,3$

FITEM, 2, 29

FITEM, 2, 30

FITEM, 2, 31

FITEM, 2, 32

A, P $51 X$

/VIEW $, 1, .3,-1, .5$

/VUP, 1, Z

/REPLOT

aplo

FLST , 2, 1, 5, ORDE, 1

FITEM, 2, 1

VEXT, P51X, , , 0, 0, depth, , , ,

FLST , 2, 1, 5, ORDE, 1 
FITEM, 2, 4

VEXT, P51X, , , 0,0,-wafer-depth, , ,

$\mathrm{FLST}, 2,1,5, \mathrm{ORDE}, 1$

FITEM, 2, 2

VEXT, P51X, , , 0, 0,-wafer, , ,

FLST, 2, 1, 5, ORDE, 1

FITEM, 2, 3

VEXT, P51X, , , 0, 0, SiO2, ,

FLST, 2, 1, 5, ORDE, 1

FITEM, 2, 5

VEXT, P51X, , , 0, 0, wafer, , ,

FLST, 2, 2, 6, ORDE, 2

FITEM, 2, 2

FITEM, 2,-3

VADD, P51X

$\mathrm{K}, \quad 25$, ,

$K, \quad 25+$ heatw2, ,

LSTR, 41, 42

$\mathrm{K}, \quad, 50,10$,

$\mathrm{K}$, , 50+heatw1, 10, ,

LSTR, 59, 60

$\mathrm{K}, \quad 30,535$,

$\mathrm{K}$, , 30,535-heatw1, ,

LSTR, 61, 62

$\mathrm{K}$, , 55, 10, ,

$\mathrm{K}$, , 55, 10+heatw1, ,

LSTR, 63, 64

$\mathrm{K}, \quad, 70,10$,

$\mathrm{K}, \quad, 70$ +heatw1,10, ,

LSTR, 65, 66

ADRAG, 48, , , , , , 1

ADRAG, $55,,,,,, 2$

ADRAG, $49,,,,,, 3$

ADRAG, 56, , ', ',

ADRAG,

$57,,,$, ,

FLST , 2, 5, 5, ORDE , 4

FITEM, 2, 12

FITEM, 2, 16

FITEM, 2, -18

FITEM, 2, 24

AADD, P51X

FLST, 2, 1, 5, ORDE, 1

FITEM, 2, 41

VEXT, P51X, , ,0,0, -heatthk, ,

vplo

/AUTO, 1

$/ \mathrm{REP}, \mathrm{FAST}$

FLST , 2, 2, 6, ORDE, 2

FITEM, 2, 1

FITEM, 2,-2

VADD, P51X

FLST, 2, 4, 6, ORDE, 2

FITEM, 2, 3

FITEM, 2, -6

VGLUE, P51X

!Mesh

FLST , 5, 2, 6, ORDE, 2

FITEM, 5, 1

FITEM, 5, -2

$\mathrm{CM}, \mathrm{Y}, \mathrm{VOLU}$

VSEL, , , ,P51X

$\mathrm{CM}, \mathrm{Y} 1, \mathrm{VOLU}$

CMSEL, S, Y

CMSEL, S, Y1 


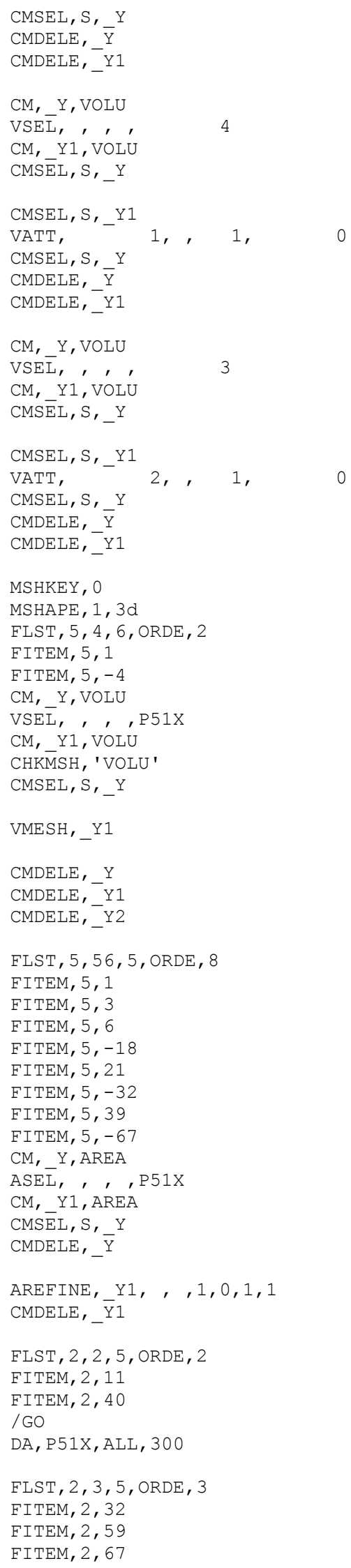


/GO

SFA, P51X, 1, CONV, 12/1e12, 300

FLST, 2, 1, 4, ORDE, 1

FITEM, 2, 99

/ GO

DL, P51X， ,ALL, 500, 0

sbctran

FINISH

/SOL

/STATUS, SOLU

SOLVE

FINISH

/POST1

/EFACET, 1

PLNSOL, TEMP, , 0 